\title{
Study of New Thiazole Based Pyridine Derivatives as Potential Corrosion Inhibitors for Mild Steel: Theoretical and Experimental Approach
}

\author{
T. K. Chaitra, ${ }^{1}$ K. N. Mohana, ${ }^{1}$ and H. C. Tandon ${ }^{2}$ \\ ${ }^{1}$ Department of Studies in Chemistry, Manasagangotri, University of Mysore, Mysuru, Karnataka 570006, India \\ ${ }^{2}$ Department of Chemistry, Sri Venkateswara College, Dhaula Kuan, New Delhi 110021, India \\ Correspondence should be addressed to K. N. Mohana; drknmohana@gmail.com
}

Received 11 September 2015; Revised 16 January 2016; Accepted 17 January 2016

Academic Editor: Michael J. Schütze

Copyright @ 2016 T. K. Chaitra et al. This is an open access article distributed under the Creative Commons Attribution License, which permits unrestricted use, distribution, and reproduction in any medium, provided the original work is properly cited.

\begin{abstract}
Three new thiazole based pyridine derivatives 5-(4-methoxy-phenyl)-thiazole-2-carboxylic acid pyridin-2-ylmethylene-hydrazide (2-MTPH), 5-(4-methoxy-phenyl)-thiazole-2-carboxylic acid pyridin-3-ylmethylene-hydrazide (3-MTPH), and 5-(4-methoxyphenyl)-thiazole-2-carboxylic acid pyridin-4-ylmethylene-hydrazide (4-MTPH) were synthesized and characterized. Corrosion inhibition performance of the prepared compounds on mild steel in $0.5 \mathrm{M} \mathrm{HCl}$ was studied using gravimetric, potentiodynamic polarisation, and electrochemical impedance techniques. Inhibition efficiency has direct relation with concentration and inverse relation with temperature. Thermodynamic parameters for dissolution and adsorption process were evaluated. Polarisation study reveals that compounds act as both anodic and cathodic inhibitors with emphasis on the former. Impedance study shows that decrease in charge transfer resistance is responsible for effective protection of steel surface by inhibitors. The film formed on the mild steel was investigated using FTIR, SEM, and EDX spectroscopy. Quantum chemical parameters like $E_{\mathrm{HOMO}}, E_{\mathrm{LUMO}}, \Delta E$, hardness, softness, and ionisation potential were calculated. Higher value of $E_{\mathrm{HOMO}}$ and lower value of $\Delta E$ indicate the better inhibition efficiency of the compounds. Lower ionisation potential of inhibitors indicates higher reactivity and lower chemical stability.
\end{abstract}

\section{Introduction}

Mild steel (MS) is used in various aspects of our lives, from footwear to household, industry to hospitals, automobiles to aircrafts, construction materials to pipelines, and so forth. The use of hydrochloric acid in pickling of MS, acidization of oil wells, and cleaning of scales is more economical, efficient, and trouble-free compared to other mineral acids [1]. During picking, hot acid solutions are used for removing oxide scales which leads to deterioration of steel caused by corrosion. The service life of steel can be extended by modifying either surface of the metal or the local environment to which metal is exposed [2]. The addition of corrosion inhibitors is a useful approach to protect MS surfaces from corrosion damage [3].

Considerable efforts are made to synthesize new organic molecules offering various molecular structures. The most synthesized compounds are the nitrogen-heterocyclic compounds which are known to be excellent complex or chelate forming substances with metals of transition series [4]. Also, the heterocyclic compounds containing nitrogen atoms can be easily protonated in acidic medium to exhibit good inhibitory action [5]. It has been pointed out that sulphur containing organic compounds have better inhibitive efficiency due to better electron donor capacity and easy polarisability [6]. On the whole, an assortment of organic compounds having two or more heteroatoms such as $\mathrm{O}$, $\mathrm{N}, \mathrm{S}$, and multiple bonds in their molecular structure is of particular interest because of their better inhibition efficiency as compared to those containing $\mathrm{N}$ or $\mathrm{S}$ alone [7]. Many investigators have chosen nitrogen and sulphur containing heterocycles as inhibitors for MS and come out with excellent results [8-13].

In continuation of our previous work [14-16], the present investigation is aimed at synthesizing three isomeric derivatives of pyridine, 5-(4-methoxy-phenyl)thiazole-2-carboxylic acid pyridin-2-ylmethylene-hydrazide 
(2-MTPH), 5-(4-methoxy-phenyl)-thiazole-2-carboxylic acid pyridin-3-ylmethylene-hydrazide (3-MTPH), and 5-(4-methoxy-phenyl)-thiazole-2-carboxylic acid pyridin4-ylmethylene-hydrazide (4-MTPH), characterise the compounds using FTIR, ${ }^{1} \mathrm{H}$ NMR, and mass spectral studies, and study their inhibition efficiency on $\mathrm{MS}$ in $0.5 \mathrm{M} \mathrm{HCl}$ using weight loss, Electrochemical Impedance Spectroscopy (EIS), and potentiodynamic polarisation techniques. Surface morphology of the compounds was studied using SEM and EDX.

Quantum chemical calculations were used to emphasise experimental data obtained from weight loss, electrochemical and morphological studies. Many quantum chemical parameters were calculated and discussed to establish the relationship between molecular and electronic structure with inhibition efficiency. By the calculation of various quantum chemical parameters, donor-acceptor interactions can be understood; from this adsorption ability of the inhibitor could be predicted. The results of quantum chemical methods were correlated with experimental results.

\section{Experimental}

2.1. Materials and Sample Preparation. All the experimental procedures using MS were executed using MS specimen of chemical composition by wt.\% C: $0.051 ; \mathrm{Mn}$ : 0.179; Si: 0.006; P: 0.005; S: 0.023; Cr: 0.051; Ni: 0.05; Mo: 0.013; Ti: 0.004; Al: 0.103; Cu: 0.050; Sn: 0.004; B: 0.00105; Co: 0.017; Nb: 0.012; $\mathrm{Pb}$ : 0.001; and the remaining iron. The dimension of coupons used for the experiment is $2 \mathrm{~cm} \times 2 \mathrm{~cm} \times 0.1 \mathrm{~cm}$. Before commencement of gravimetric and electrochemical experiments, surface of the samples was polished under running tap water using silicon carbide emery paper (grade of 600,800 , and 1200), washed thoroughly with double distilled water, dried on a clean tissue paper, and immersed in benzene for 5 seconds followed by drying using acetone. The specimens were kept in desiccator until use. At the end of the test, the specimens were carefully washed with benzene and acetone, dried, and then weighed. For polarisation and impedance measurements, the MS specimens were embedded in epoxy resin to expose a geometrical surface area of $1 \mathrm{~cm}^{2}$ to the electrolyte. Stock solution was prepared by dissolving appropriate amount of inhibitor in $0.5 \mathrm{M} \mathrm{HCl}$. A concentration range of $0.22 \mathrm{mM}$ to $0.88 \mathrm{mM}$ was prepared from stock solution in $0.5 \mathrm{M} \mathrm{HCl}$. Melting range of the inhibitors was found out using Veego melting point VMP III apparatus.

2.2. Synthesis of Inhibitors. Scheme for the synthesis of inhibitors 2-MTPH, 3-MTPH, and 4-MTPH is outlined in Figure 1. The procedure for the synthesis of inhibitors is briefed in 5 steps. The chemical structure, IUPAC name, yield, and melting points are listed in Table 1.

Synthesis of $\mathrm{N}$-[2-(4-Methoxy-phenyl)-2-oxo-ethyl]-oxalamic Acid Ethyl Ester (Compound 3). According to the reported procedure [17], compound 3 was prepared. To a solution of 1 equivalent of 2-amino-1-(4-methoxyphenyl)-ethanone hydrochloride in dry MDC $(10 \mathrm{~mL}), 3$ equivalents of trimethylamine were added followed by 1 equivalent of chloro-oxo acetic acid ethyl ester at $0^{\circ} \mathrm{C}$. The reaction mixture was allowed to warm up to room temperature and stirred for $16 \mathrm{~h}$. The reaction was checked for completion using TLC with solvent system ethyl acetate: methanol $(9: 1)$. The mixture was then diluted with water and extracted with ethyl acetate. The organic layer was washed with water followed by brine solution, concentrated under reduced pressure, dried over sodium sulphate, and recrystallized from ethanol to get pure product.

Synthesis of 5-(4-Methoxy-phenyl)-thiazole-2-carboxylic Acid Ethyl Ester (Compound 4). According to the reported procedure [17], to a mixture of 1 equivalent of compound 3 and $10 \mathrm{~mL}$ of dry chloroform, 2 equivalents of phosphorus pentasulfide were added. The resulting mixture was heated to reflux for 4 hours. The reaction was checked for completion using TLC with solvent system ethyl acetate : methanol $(9: 1)$. The reaction mixture was quenched with water and extracted with chloroform. The organic layer was washed with water followed by brine solution, dried over anhydrous sodium sulphate, concentrated under reduced pressure, and recrystallized from ethanol.

Synthesis of 5-(4-Methoxy-phenyl)-thiazole-2-carboxylic Acid Hydrazide (Compound 5). According to reported procedure [18], compound 4 obtained from previous step along with equimolar hydrazine hydrate and 10 volumes of ethanol was taken in $\mathrm{RB}$ flask and refluxed for 5 hours at $80^{\circ} \mathrm{C}$. Completion of the reaction was checked using TLC with mobile phase $\mathrm{MDC}: \mathrm{MeOH}(9: 1)$. After the completion, reaction mixture was brought to $0-5^{\circ} \mathrm{C}$ and stirred for 2 hours to get precipitate. The reaction mixture was filtered, washed with chilled ethanol, and dried to get the product.

Synthesis of 5-(4-Methoxy-phenyl)-thiazole-2-carboxylic Acid Pyridin-2-ylmethylene-hydrazide (Compound 6), 5-(4-Metz hoxy-phenyl)-thiazole-2-carboxylic Acid Pyridin-3-ylmethylene-hydrazide (Compound 7), and 5-(4-Methoxy-phenyl)thiazole-2-carboxylic Acid Pyridin-4-ylmethylene-hydrazide (Compound 8). According to the literature [19], compound 5 was taken in three RB flasks separately with equimolar amounts of three different aldehydes (pyridine-2-carbaldehyde, pyridine-3-carbaldehyde, and pyridine-4-carbaldehyde) and 10 volumes of ethanol. The reaction mixture was refluxed for 6 hours. The reaction was monitored for completion using TLC with mobile phase MDC:MeOH $(9: 1)$. After the completion, the reaction mixture was cooled, filtered, and recrystallized from ethanol to get pure product.

\subsubsection{Spectral Data}

5-(4-Methoxy-phenyl)-thiazole-2-carboxylic Acid Pyridin-2ylmethylene-hydrazide (2-MTPH). IR $\left(\mathrm{cm}^{-1}\right) 1609(\mathrm{C}=\mathrm{N}$ stretching), 1684 ( $\mathrm{C}=\mathrm{O}$ stretching), 3114 ( $\mathrm{N}-\mathrm{H}$ stretching), 1450 ( $\mathrm{H}_{2} \mathrm{C}-\mathrm{H}$ deformation), 1465-1585 (Ar C=C). ${ }^{1} \mathrm{H}-\mathrm{NMR}$ $\left(400 \mathrm{MHz}, \mathrm{DMSO}-\mathrm{d}_{6}\right) \delta_{\mathrm{H}}$ ppm: $3.822\left(\mathrm{~s}, 3 \mathrm{H}, \mathrm{O}-\mathrm{CH}_{3}\right), 7.054$ (s, 1H, H-C=N), 7.075 (d, 2H, Ar-H), 7.457 (d, 2H, Ar-H), 7.891 


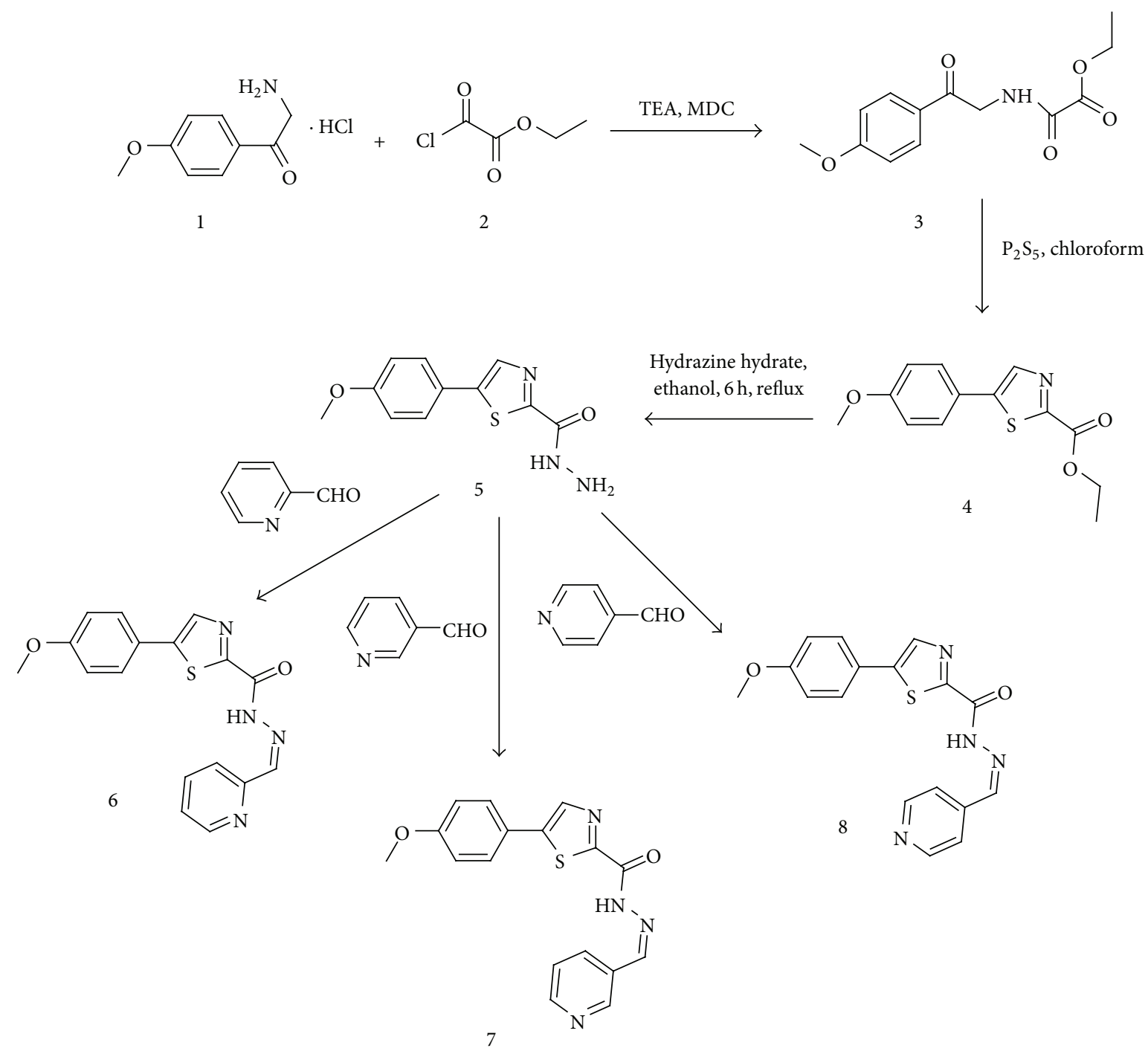

FIGURE 1: Scheme for the synthesis of inhibitors.

(t, 1H, Ar-H), 7.929 (t, 1H, Ar-H), 8.06 (d, 1H, Ar-H), 8.13 (s, $1 \mathrm{H}$, thiazole-H), 8.369 (s, 1H, Ar-H), 12.41 (s, 1H, N-H). MS: $339.18(\mathrm{M}+1), 340.18(\mathrm{M}+2), 341.18(\mathrm{M}+3)$.

5-(4-Methoxy-phenyl)-thiazole-2-carboxylic Acid Pyridin-3ylmethylene-hydrazide (3-MTPH). IR $\left(\mathrm{cm}^{-1}\right) 1606(\mathrm{C}=\mathrm{N})$, $1657(\mathrm{C}=\mathrm{O}), 3241(\mathrm{~N}-\mathrm{H}), 1435\left(\mathrm{H}_{2} \mathrm{C}-\mathrm{H}\right), 1480-1589$ ( $\left.\mathrm{Ar} \mathrm{C}=\mathrm{C}\right)$. ${ }^{1} \mathrm{H}-\mathrm{NMR}\left(400 \mathrm{MHz}, \mathrm{DMSO}-\mathrm{d}_{6}\right) \delta_{\mathrm{H}}$ ppm: 3.824 (s, 3H, O$\mathrm{CH}_{3}$ ), 7.502 (s, 1H, H-C=N), 7.535 (t, 1H, Ar-H), 8.13 (s, 1H, thiazole-H), 8.15 (d, 2H, Ar-H), 8.364 (d, 1H, Ar-H), 8.64 (d, 2H, Ar-H), 8.871 (s, 1H, Ar-H), 8.833 (d, 1H, Ar-H), 12.32 (s, 1H, N-H). MS: $339.18(\mathrm{M}+1), 340.18(\mathrm{M}+2), 341.18(\mathrm{M}+3)$.

5-(4-Methoxy-phenyl)-thiazole-2-carboxylic Acid Pyridin-2ylmethylene-hydrazide (4-MTPH). IR $\left(\mathrm{cm}^{-1}\right) 1607(\mathrm{C}=\mathrm{N})$, 1660 (C=O), 3246 (N-H), $1446\left(\mathrm{H}_{2} \mathrm{C}-\mathrm{H}\right), 1480-1590$ ( $\mathrm{Ar}$ $\mathrm{C}=\mathrm{C}) .{ }^{1} \mathrm{H}-\mathrm{NMR}\left(400 \mathrm{MHz}, \mathrm{DMSO}-\mathrm{d}_{6}\right) \delta_{\mathrm{H}} \mathrm{ppm}: 3.826(\mathrm{~s}$, $3 \mathrm{H}, \mathrm{O}-\mathrm{CH}_{3}$ ), 7.132 (s, 1H, H-C=N), 7.153 (d, 2H, Ar-H), 7.527 (d, 2H, Ar-H), 8.213 (s, 1H, thiazole-H), 8.563 (d, 2H, Ar-H),
8.743 (d, 2H, Ar-H), 12.52 (s, 1H, N-H). MS: $339.18(\mathrm{M}+1)$, $340.18(\mathrm{M}+2), 341.18(\mathrm{M}+3)$.

2.3. Weight Loss Measurements. MS coupons were immersed in $0.5 \mathrm{M} \mathrm{HCl}$ without and with varying amount of the inhibitor for 4 hours in a thermostatically controlled water bath (with an accuracy of $\pm 0.2^{\circ} \mathrm{C}$ ) at constant temperature, under aerated condition (Weber Limited, Chennai, India). The specimens were taken out after 4 hours of immersion and rinsed in water followed by drying in acetone. Weight loss of the specimens was recorded by analytical balance (Sartorius, precision $\pm 0.1 \mathrm{mg}$ ). Experiment was carried out in triplicate and average weight loss of three similar specimens was calculated. The procedure was repeated for all other concentrations and temperatures.

2.4. Electrochemical Measurements. Potentiodynamic polarisation and Electrochemical Impedance Spectroscopy (EIS) 
TABLE 1: Abbreviations, IUPAC names, molecular structure, and melting points of inhibitors.

\begin{tabular}{|c|c|c|c|c|}
\hline Inhibitor & IUPAC name & Structure of the inhibitor & Yield (\%) & Melting point $\left({ }^{\circ} \mathrm{C}\right)$ \\
\hline 2-МТРН & $\begin{array}{l}\text { 5-(4-Methoxy-phenyl)-thiazole-2- } \\
\text { carboxylic acid } \\
\text { pyridin-2-ylmethylene-hydrazide }\end{array}$ & & 82 & $175-177$ \\
\hline 3-МТРН & $\begin{array}{l}\text { 5-(4-Methoxy-phenyl)-thiazole-2- } \\
\text { carboxylic acid } \\
\text { pyridin-3-ylmethylene-hydrazide }\end{array}$ & & 80 & $174-176$ \\
\hline 4-МТРН & $\begin{array}{l}\text { 5-(4-Methoxy-phenyl)-thiazole-2- } \\
\text { carboxylic acid } \\
\text { pyridin-4-ylmethylene-hydrazide }\end{array}$ & & 83 & $170-172$ \\
\hline
\end{tabular}

experiments were carried out using a CHI660D electrochemical workstation. A conventional three-electrode cell consisting of $|\mathrm{Ag} / \mathrm{AgCl}|$ reference electrode, a platinum auxiliary electrode, and the working MS electrode with $1 \mathrm{~cm}^{2}$ exposed areas was used. The specimens were pretreated in the same way as gravimetric measurements. The electrochemical tests were performed using the synthesized thiazole based pyridine derivatives for various concentrations ranging from $0.22 \mathrm{mM}$ to $0.88 \mathrm{mM}$ at $30^{\circ} \mathrm{C}$. Potentiodynamic polarisation measurements were performed in the potential range from -850 to $-150 \mathrm{mV}$ with a scan rate of $0.4 \mathrm{mVs}^{-1}$. Prior to EIS measurements, half an hour was spent making open circuit potential a stable value. EIS data were taken using AC sinusoidal signal in the frequency range 1 to $1,00,000 \mathrm{~Hz}$ with amplitude $0.005 \mathrm{~V}$. Simulation of results and fitting of the curve are done using the built-in software of the electrochemical work station.

2.5. Quantum Chemical Calculations. The geometrical optimization of the investigated molecules has been done by $\mathrm{Ab}$ initio method at $631 \mathrm{G}^{*}$ basis set for all atoms. For energy minimization, the convergence limit at 1.0 and $\mathrm{rms}$ gradient $1.0 \mathrm{kcal} / \mathrm{A}$ mol has been kept. The Polak-Ribiere conjugate gradient algorithm which is quite fast and precise is used for optimization of geometry. The HYPERCHEM 7.52 professional software is employed for all calculations.
2.6. Scanning Electron Microscopy (SEM) and EDX Spectroscopy. The SEM experiments were performed using a Zeiss electron microscope with the working voltage of $15 \mathrm{kV}$ and the working distance of $10.5 \mathrm{~mm}$. In SEM micrographs, the specimens were exposed to the $0.5 \mathrm{M} \mathrm{HCl}$ in the absence and presence of three inhibitors under optimum condition after $4 \mathrm{~h}$ of immersion. The SEM images were taken for polished MS specimen and specimen immersed in acid solution with and without inhibitors. EDX experiments were performed using FESEM quanta 200 FEI instrument.

\section{Results and Discussion}

\subsection{Weight Loss Measurements}

3.1.1. Effect of Inhibitor Concentration. Weight loss study was conducted for MS specimens in $0.5 \mathrm{M} \mathrm{HCl}$ containing various concentrations of inhibitors (2-MTPH, 3-MTPH, and 4$\mathrm{MTPH}$ ) for 4 hours of immersion between $30^{\circ} \mathrm{C}$ and $60^{\circ} \mathrm{C}$ and the values of corrosion rate and inhibition efficiency are depicted in Table 2. The corrosion rate and inhibition efficiency can be calculated using

$$
\begin{aligned}
C_{R} & =\frac{\Delta W}{S t}, \\
\% \mathrm{IE} & =\frac{\left(C_{R}\right)_{a}-\left(C_{R}\right)_{p}}{\left(C_{R}\right)_{a}} \times 100,
\end{aligned}
$$




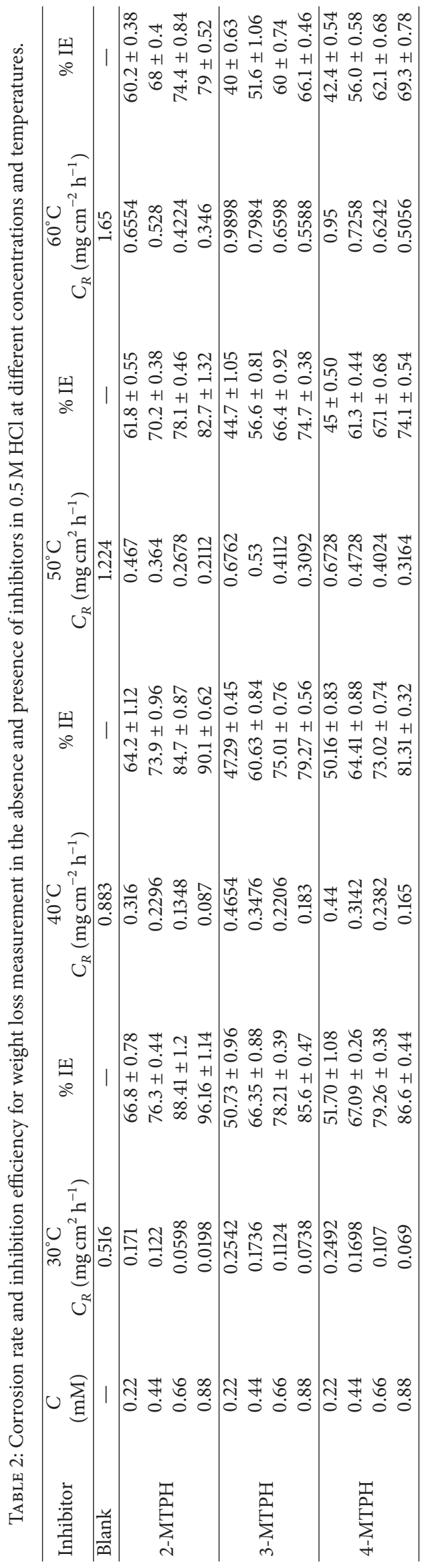


TABLE 3: Kinetic and activation parameters in the absence and presence of inhibitors in $0.5 \mathrm{M} \mathrm{HCl}$.

\begin{tabular}{|c|c|c|c|c|c|c|}
\hline Inhibitor & $C(\mathrm{mM})$ & $E_{a}^{*}\left(\mathrm{~kJ} \mathrm{~mol}^{-1}\right)$ & $K\left(\mathrm{mg} \mathrm{cm}^{-2} \mathrm{~h}^{-1}\right)$ & $\Delta H_{a}^{*}\left(\mathrm{~kJ} \mathrm{~mol}^{-1}\right)$ & $\Delta H_{a}{ }^{*}=E_{a}{ }^{*}-R T\left(\mathrm{~kJ} \mathrm{~mol}^{-1}\right)$ & $\Delta S_{a}^{*}\left(\mathrm{~J} \mathrm{~mol}^{-1} \mathrm{~K}^{-1}\right)$ \\
\hline Blank & - & 32.1 & 186465 & 30.5 & 29.5 & -152.9 \\
\hline \multirow{4}{*}{ 2-МТРН } & 0.22 & 37.2 & 473070 & 34.6 & 34.6 & -145.1 \\
\hline & 0.44 & 40.8 & 1416925 & 38.2 & 38.2 & -136.0 \\
\hline & 0.66 & 55.1 & 201439571 & 52.5 & 52.5 & -94.8 \\
\hline & 0.88 & 79.9 & $1.471 \times 10^{12}$ & 77.3 & 77.3 & -20.8 \\
\hline \multirow{4}{*}{ 3-МТРН } & 0.22 & 37.4 & 762989 & 34.8 & 34.8 & -141.1 \\
\hline & 0.44 & 42.1 & 3311792 & 39.4 & 39.5 & -128.9 \\
\hline & 0.66 & 49.8 & 45127393 & 47.2 & 47.2 & -107.2 \\
\hline & 0.88 & 55.5 & $2.93 \times 10^{8}$ & 52.8 & 52.8 & -91.7 \\
\hline \multirow{4}{*}{ 4-МТРН } & 0.22 & 37.3 & 711407 & 34.7 & 34.7 & -141.7 \\
\hline & 0.44 & 40.1 & 1426879 & 37.4 & 37.4 & -135.9 \\
\hline & 0.66 & 48.9 & 31737198 & 46.3 & 46.3 & -110.1 \\
\hline & 0.88 & 55.8 & $3.07 \times 10^{8}$ & 53.1 & 53.1 & -91.3 \\
\hline
\end{tabular}

where $\Delta W$ is the weight loss, $S$ is the surface area of the specimen $\left(\mathrm{cm}^{2}\right), t$ is the immersion time $(\mathrm{h})$, and $\left(C_{R}\right)_{a}$, $\left(C_{R}\right)_{p}$ are corrosion rates in the absence and presence of the inhibitor, respectively.

The inhibition efficiency was seen to increase with additive concentration up to the optimum level after which there is no significant change. 2-MTPH, 3-MTPH, and 4MTPH displayed maximum corrosion inhibition efficiency at concentration of $0.88 \mathrm{mM}$ yielding $96.16 \%, 85.6 \%$, and $86.6 \%$, respectively. After optimization, a series of concentrations from $0.22 \mathrm{mM}$ to $0.88 \mathrm{mM}$ was chosen to study the inhibition behavior of three isomeric derivatives of pyridine on MS. Enhancement in surface coverage due to availability of larger number of molecules can account for significant change in corrosion rate after the increase in concentration of inhibitors. The presence of electron rich group like $-\mathrm{OCH}_{3}$, plenty of $\pi$-electrons, $>\mathrm{C}=\mathrm{N}$ - bond, and lone pair of electrons on the $\mathrm{N}$ and $\mathrm{S}$ atoms are the factors responsible for good inhibition efficiency at low concentration.

3.1.2. Activation and Thermodynamic Parameters. Temperature has marked effect on the rate of corrosion process. The effect of temperature on inhibition reaction is highly complex, because many changes may occur on the metal surface such as rapid etching, rupture, desorption of inhibitor, and the decomposition and/or rearrangement of inhibitor [20]. To study the influence of temperature on the rate of corrosion, weight loss experiments were carried out in the presence and absence of inhibitors at various temperatures from $30^{\circ} \mathrm{C}$ to $60^{\circ} \mathrm{C}$. Corrosion rate increased with increase in temperature in both inhibited and uninhibited solutions but increased more rapidly in uninhibited solution. It is clear from Table 2 that inhibition efficiency of all three inhibitors shows maximum value at $30^{\circ} \mathrm{C}$ at all four concentrations. Such type of behavior can be described as the increase in temperature that leads to a shift of the equilibrium constant towards desorption of the inhibitor molecules at the surface of MS [21].

As the present study focuses on thermodynamic and activation parameters it is evident to study Arrhenius equation because corrosion reactions are typically regarded as Arrhenius type processes. Corrosion rate is related to temperature by the following equation:

$$
C_{R}=k \exp \left(-\frac{E_{a}^{*}}{R T}\right)
$$

where $E_{a}{ }^{*}$ is the apparent activation corrosion energy, $R$ is the universal gas constant, and $k$ is the Arrhenius preexponential constant and $T$ is the absolute temperature. An alternate form of Arrhenius equation which is also called transition state equation can be written as

$$
C_{R}=\frac{R T}{N h} \exp \left(\frac{\Delta S_{a}^{*}}{R}\right) \exp \left(\frac{-\Delta H_{a}^{*}}{R T}\right),
$$

where $\Delta S_{a}{ }^{*}$ is the entropy of activation, $\Delta H_{a}{ }^{*}$ is the enthalpy of activation, $N$ is Avogadro's number, and $h$ is Planck's constant. Making use of (2), a plot of $\ln C_{R}$ versus $1 / T$ was drawn to obtain a straight line (Figure 2). Computing the values of slope and intercept, the values of $E_{a}{ }^{*}$ and $k$ were obtained for three inhibitors at four different concentrations. Using (3), another linear plot of $\ln C_{R} / T$ versus $1 / T$ was drawn (Figure 3) with slope $\left(-\Delta H_{a}{ }^{*} / R\right)$ and intercept $[\ln (R / N h)+$ $\left.\Delta S_{a}{ }^{*} / R\right]$. All values are listed in Table 3 .

The activation energy for uninhibited solution is less compared to inhibited solutions. The increase in concentration of 2-MTPH, 3-MTPH, and 4-MTPH (from to $0.22 \mathrm{mM}$ to $0.88 \mathrm{mM}$ ) increased the activation energies for the corrosion of $\mathrm{MS}$ in $0.5 \mathrm{M} \mathrm{HCl}$ (Table 3). Among three inhibitors, 2-MTPH showed highest activation energy of $79.92 \mathrm{~kJ} \mathrm{~mol}^{-1}$. The increase in $E_{a}$ with the addition of inhibitors is related to concurrent increase in the energy barrier which prevents charge and mass transfer of inhibitor molecules by adsorption on the MS surface. Since the value of activation energy is above $20 \mathrm{~kJ} \mathrm{~mol}^{-1}$, the whole process is under surface control [22]. Positive value of $\Delta H_{a}{ }^{*}$ indicates the endothermic nature of steel dissolution process in the presence and absence of inhibitors. Higher value of $\Delta H_{a}{ }^{*}$ in the presence of inhibitors shows the higher difficulty for the dissolution of 


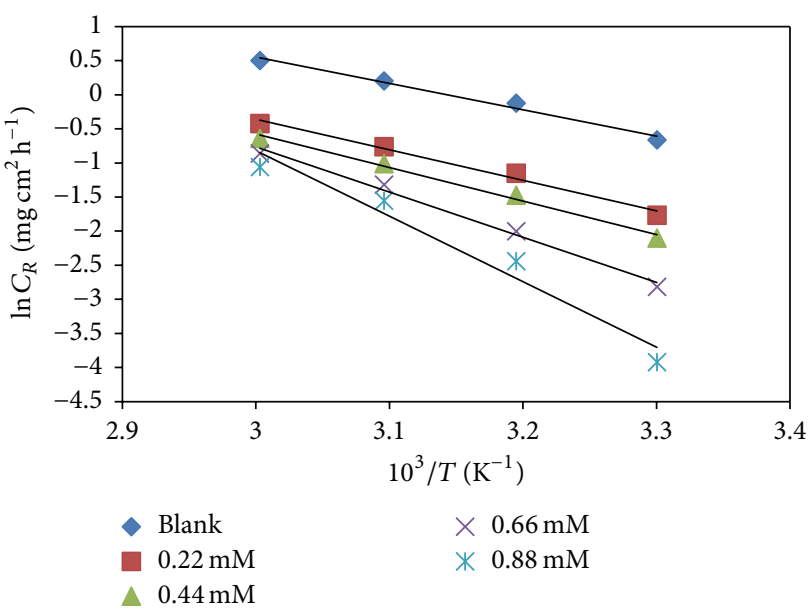

(a)

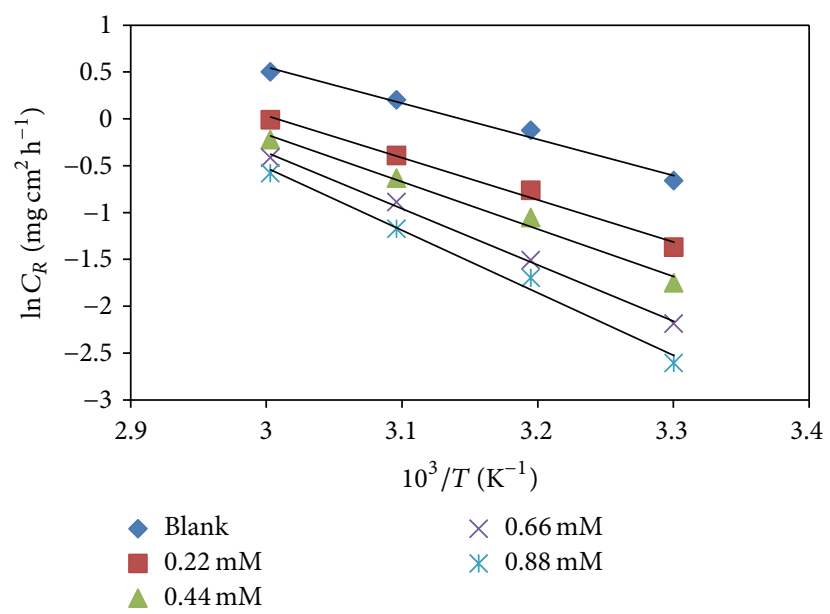

(b)

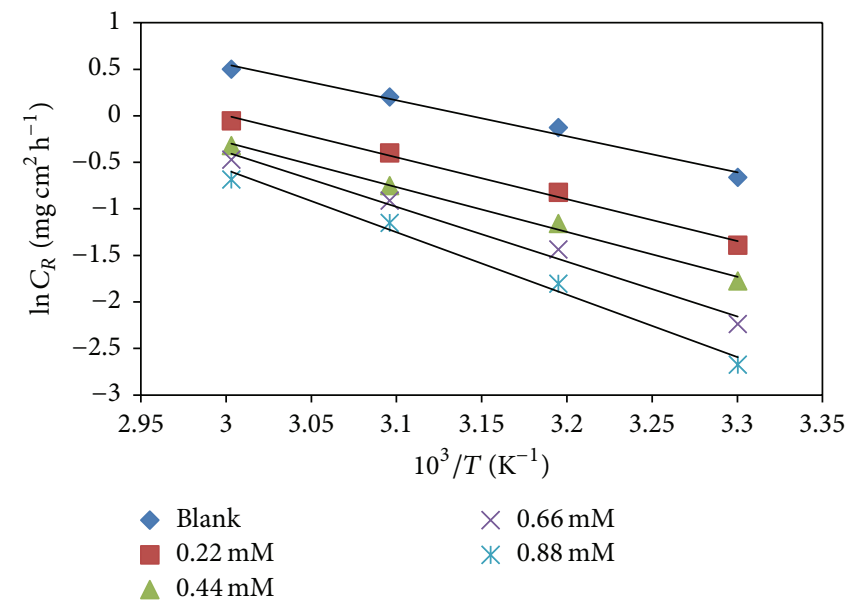

(c)

FIGURE 2: Arrhenius plots in the absence and presence of different concentrations of (a) 2-MTPH, (b) 3-MTPH, and (c) 4-MTPH.

MS in the presence of 2-MTPH, 3-MTPH, and 4-MTPH. Negative value of activation entropy indicates that the activated complex in the rate determination step is association rather than dissociation. That is, decrease in disorderness takes place on moving from reactants to activated complex [23].

3.1.3. Adsorption Isotherm. It is well known that organic inhibitors establish inhibition by adsorption onto the metal surface. The adsorption of inhibitors is influenced by the chemical structures of organic compounds, nature and surface charge of metal, the distribution of charge in molecule, and type of aggressive media [24, 25]. Adsorption isotherm experiments were performed to have more insights into the mechanism of corrosion inhibition since it explains the molecular interactions of the inhibitor molecules with the active sites on the MS surface [26]. The adsorption on the corroding surfaces never reaches the real equilibrium and tends to reach an adsorption steady state. However, when the corrosion rate is sufficiently small, the adsorption steady state has a tendency to become a quasi-equilibrium state. In this case, it is reasonable to consider the quasiequilibrium adsorption in thermodynamic way using the appropriate equilibrium isotherms [27]. Several isotherms like Freundlich, Langmuir, and Temkin were tried to characterize the inhibition mechanism. All of these isotherms have the general form

$$
f(\theta, x) \exp (-2 \alpha \theta)=K_{\mathrm{ads}} C,
$$

where $f(\theta, x)$ is the configurational factor which depends upon the physical model and the assumptions underlying the derivation of the isotherm, $\theta$ is the degree of surface coverage, $C$ is the inhibitor concentration in the bulk solution, $\alpha$ is the molecular interaction, and $K_{\mathrm{ads}}$ is adsorption equilibrium constant [28].

The best fit was obtained for Langmuir adsorption isotherm which assumes that the solid surface contains fixed adsorption sites and each site holds one adsorbed species. It follows the equation

$$
\frac{C}{\theta}=\frac{1}{K_{\mathrm{ads}}}+C
$$




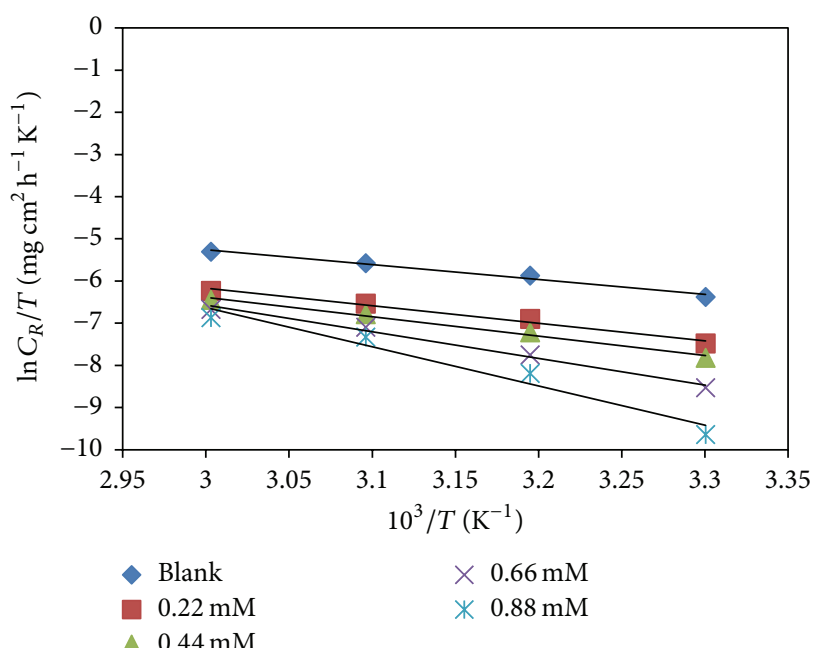

(a)

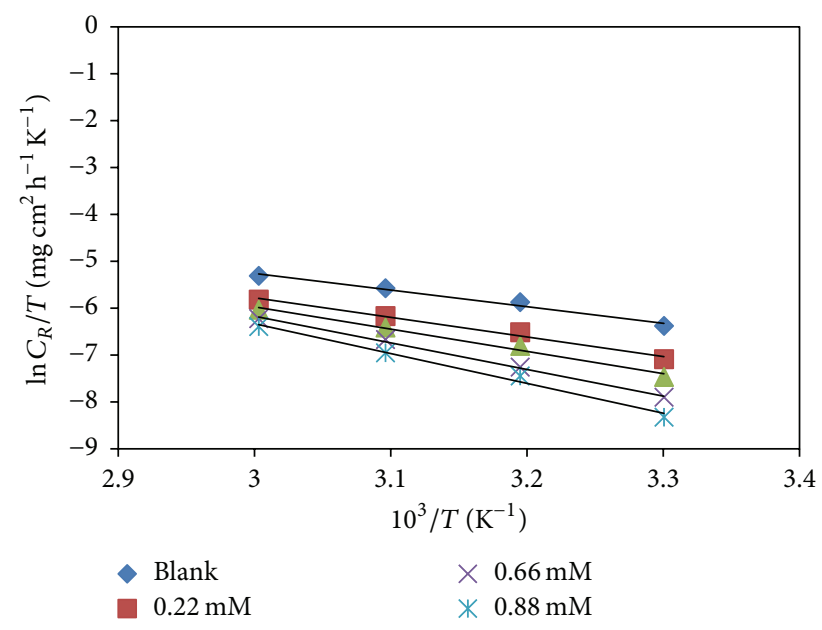

(b)

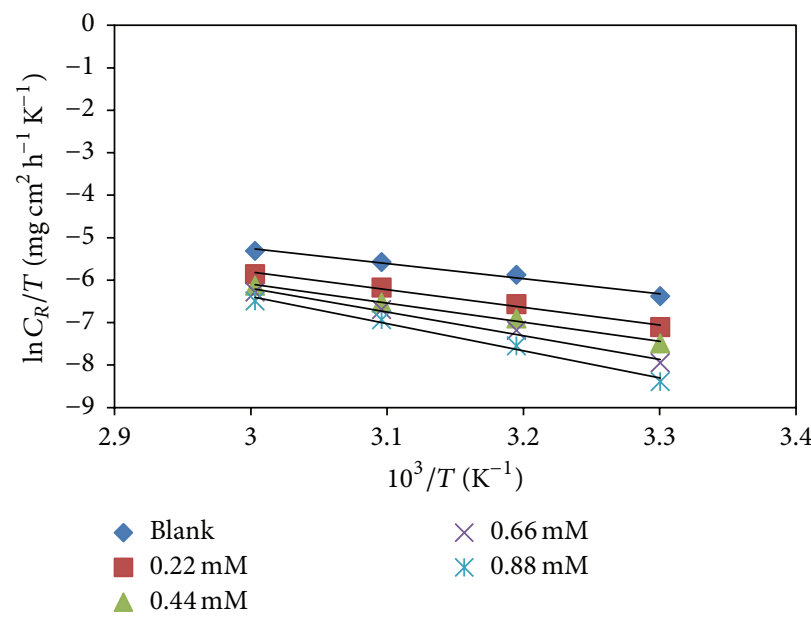

(c)

FIGURE 3: Alternative Arrhenius plots in the absence and presence of different concentrations of (a) 2-MTPH, (b) 3-MTPH, and (c) 4-MTPH.

A graph of $C / \theta$ versus $C$ was drawn for all three inhibitors and obtained straight lines (Figure 4). The slope of straight lines was approximately 1 and regression coefficient was around 0.99 (Table 4) which proves the typical Langmuir kind of adsorption. From (5) $K_{\text {ads }}$ can be calculated from intercept line on $C / \theta$ axis. Free energy of adsorption can be calculated from $K_{\text {ads }}$ using

$$
\Delta G_{\mathrm{ads}}^{o}=-R T \ln \left(55.5 K_{\mathrm{ads}}\right),
$$

where $R$ is gas constant and $T$ is the absolute temperature of the experiment and the constant value 55.5 is the concentration of water in solution in $\mathrm{mol} \mathrm{dm}^{-3}$. The $\Delta G^{o}$ ads is found to be negative indicating that adsorption of all the three inhibitors is spontaneous phenomenon and the adsorbed layer formed on the MS surface is stable. Knowing $\Delta G^{o}$ ads, we can predict the kind of adsorption. Adsorption can be either physisorption or chemisorption. Physical adsorption requires presence of both electrically charged surface of the metal and charged species in the bulk of the solution. Chemisorption occurs in the presence of a metal having vacant low-energy electron orbital and an inhibitor with molecules having relatively loosely bound electrons or heteroatoms with lone pair of electrons resulting in coordinate type of bond [29]. It is usually accepted that the value of $\Delta G^{o}$ ads around $-20 \mathrm{~kJ} \mathrm{~mol}^{-1}$ or lower indicates the physical kind of interaction whereas those around $-40 \mathrm{~kJ} \mathrm{~mol}^{-1}$ or higher indicate chemisorption between the metal surface and organic molecules [30]. The $\Delta G^{o}$ ads value for 2-MTPH, 3-MTPH, and 4-MTPH is between -30 and $-40 \mathrm{~kJ} \mathrm{~mol}^{-1}$, so the adsorption is not totally physical or chemical but a complex comprehensive kind of interaction involving both.

Entropy of adsorption and enthalpy of adsorption process can be calculated using the following thermodynamic equation:

$$
\Delta G_{\text {ads }}^{o}=\Delta H_{\text {ads }}^{o}-T \Delta S_{\text {ads }}^{o} .
$$

It is straight line form of equation with slope $-\Delta S^{o}$ ads and intercept $\Delta H^{o}$ ads (Figure 5). The values of all thermodynamic parameters are listed in Table 4 . The entropy of adsorption is positive (between 83 and $125 \mathrm{~J} \mathrm{~K}^{-1} \mathrm{~mol}^{-1}$ ) for three inhibitors. 


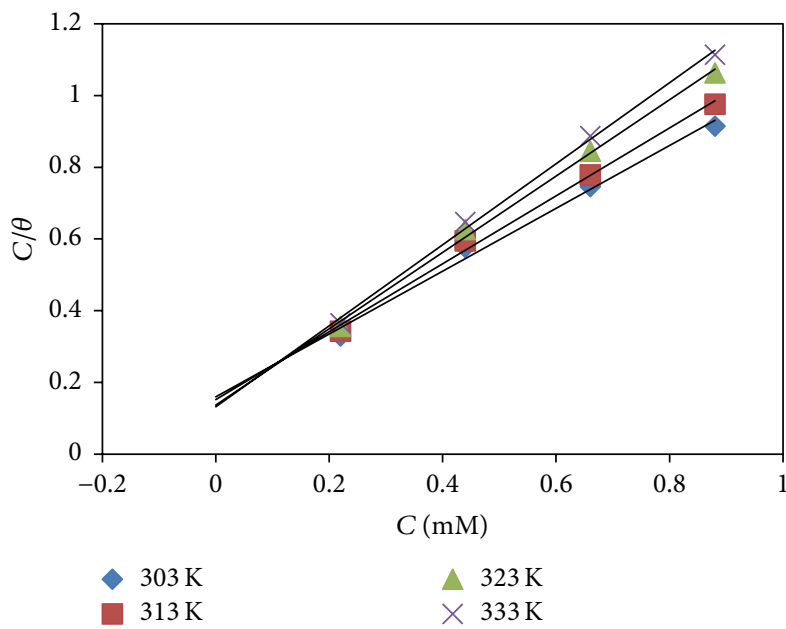

(a)

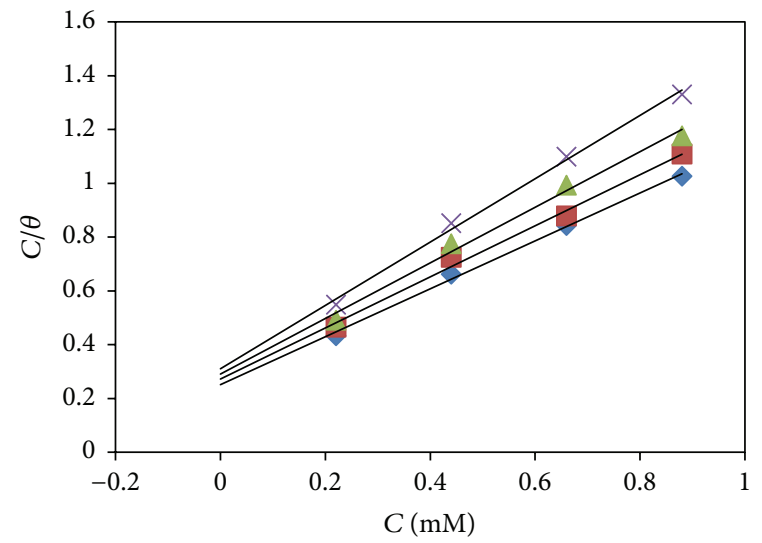

- $303 \mathrm{~K}$

$313 \mathrm{~K}$ $\triangle 323 \mathrm{~K}$
$\times 333 \mathrm{~K}$

(b)

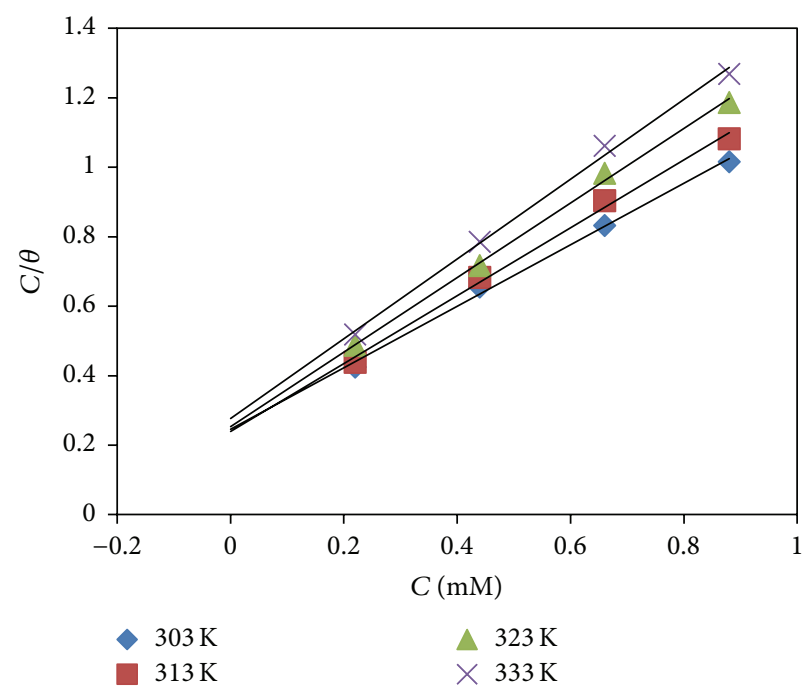

(c)

Figure 4: Langmuir isotherm for the adsorption of (a) 2-MTPH, (b) 3-MTPH, and (c) 4-MTPH on MS in $0.5 \mathrm{M} \mathrm{HCl}$ at different temperatures.

TABLE 4: Adsorption thermodynamic parameters in the absence and presence of various concentrations of inhibitors.

\begin{tabular}{|c|c|c|c|c|c|c|c|}
\hline Inhibitor & $T(\mathrm{~K})$ & $R^{2}$ & $\begin{array}{c}K_{\mathrm{ads}} \\
\left(\mathrm{L} \mathrm{mol}^{-1}\right)\end{array}$ & $\underset{\left(\mathrm{kJ} \mathrm{mol}^{-1}\right)}{\Delta G_{\mathrm{ads}}}$ & $\begin{array}{c}\Delta S_{\mathrm{ads}} \\
\left(\mathrm{J} \mathrm{mol}^{-1} \mathrm{~K}^{-1}\right)\end{array}$ & $\begin{array}{c}\Delta H_{\mathrm{ads}} \\
\left(\mathrm{kJ} \mathrm{mol}^{-1}\right)\end{array}$ & $\begin{array}{c}\Delta G_{\mathrm{ads}}= \\
\Delta H_{\mathrm{ads}}-T \Delta S_{\mathrm{ads}} \\
\left(\mathrm{kJ} \mathrm{mol}{ }^{-1}\right)\end{array}$ \\
\hline \multirow{4}{*}{ 2-MTPH } & 303 & 0.9903 & 6266 & -32.1 & \multirow{4}{*}{125} & \multirow{4}{*}{5.67} & -32.1 \\
\hline & 313 & 0.9951 & 6588 & -33.3 & & & -33.4 \\
\hline & 323 & 0.9971 & 7294 & -34.7 & & & -34.6 \\
\hline & 333 & 0.9974 & 7587 & -35.8 & & & -35.9 \\
\hline \multirow{4}{*}{ 3-МТРН } & 303 & 0.9965 & 3973 & -31.0 & \multirow{4}{*}{83} & \multirow{4}{*}{-5.84} & -31 \\
\hline & 313 & 0.9914 & 3663 & -31.8 & & & -31.8 \\
\hline & 323 & 0.9901 & 3438 & -32.7 & & & -32.6 \\
\hline & 333 & 0.9959 & 3218 & -33.5 & & & -33.5 \\
\hline \multirow{4}{*}{ 4-MTPH } & 303 & 0.9961 & 4073 & -31.1 & \multirow{4}{*}{91} & \multirow{4}{*}{-3.59} & -31.1 \\
\hline & 313 & 0.9952 & 4186 & -32.2 & & & -32.0 \\
\hline & 323 & 0.9976 & 3943 & -33.0 & & & -33 \\
\hline & 333 & 0.9963 & 3611 & -33.8 & & & -33.9 \\
\hline
\end{tabular}




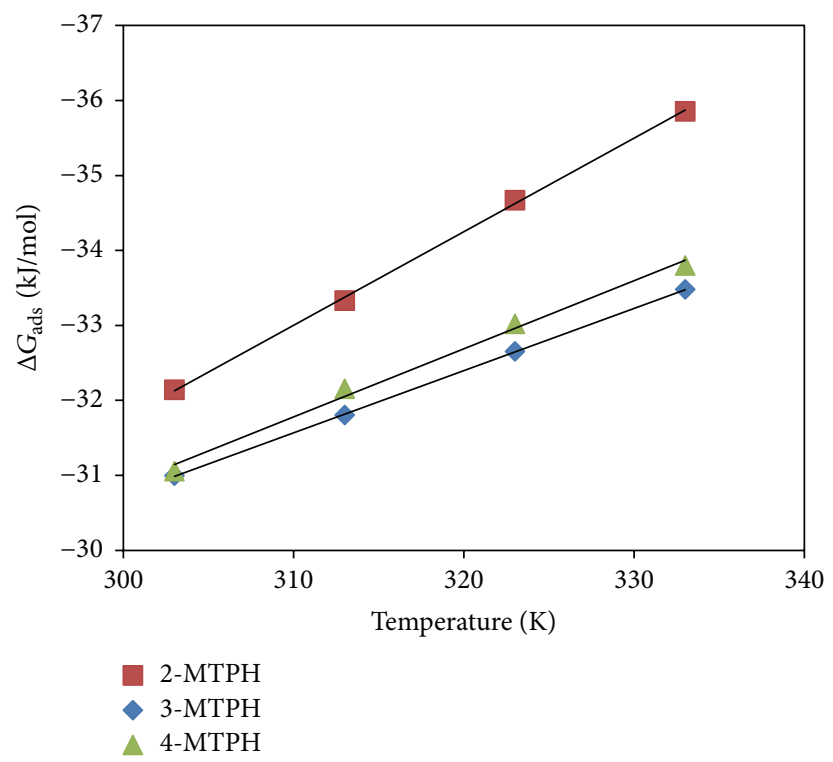

FIgure 5: Plot of $\Delta G_{\text {ads }}$ versus $T$ for 2-MTPH, 3-MTPH, and 4-MTPH.

The gain in entropy which accompanies the substitutional adsorption process is attributed to the increase in the solvent entropy. This agrees with the general suggestion that the values of $\Delta G^{o}$ ads increase with the increase of inhibition efficiency as the adsorption of organic compound is accompanied by desorption of water molecules off the surface $[31,32]$. This means that, during adsorption of Schiff bases, desorption of solute molecules takes place or the system moves to less ordered state. This increase in entropy of adsorption acts as driving force for adsorption of inhibitors on MS surface. Bentiss et al. reported that if $\Delta H^{o}$ ads $>0$ (endothermic), then adsorption is chemisorption and if $\Delta H^{o}$ ads $<0$ (exothermic), then it can be either physisorption or chemisorption. Further, in exothermic process physisorption can be distinguished from chemisorption on the basis of magnitude of $\Delta H^{o}$ ads [33]. For physisorption, enthalpy of adsorption is usually less than $40 \mathrm{~kJ} \mathrm{~mol}^{-1}$ and for chemisorption it is greater than $100 \mathrm{~kJ} \mathrm{~mol}^{-1}$ [34]. Among the three isomeric derivatives 2-MTPH has positive value of enthalpy of adsorption so the kind of adsorption is chemisorption, whereas 3-MTPH and $4-\mathrm{MTPH}$ have small and negative value $\Delta H^{o}$ ads which indicates that the adsorption is predominantly physical.

3.2. Potentiodynamic Polarisation. The anodic and cathodic behavior of MS corrosion in the absence and presence of inhibitors in $0.5 \mathrm{M} \mathrm{HCl}$ has been studied using potentiodynamic polarisation technique. Figure 6 shows the polarisation curves for MS without and with various concentrations of 2-MTPH, 3-MTPH, and 4-MTPH in $0.5 \mathrm{M}$ hydrochloric acid at $303 \mathrm{~K}$. The linear Tafel segments of anodic and cathodic curves were extrapolated to the corrosion potential axis to obtain corrosion current density $\left(i_{\text {corr }}\right)$. Different corrosion parameters such as the corrosion potential $\left(E_{\text {corr }}\right)$, corrosion current density $\left(i_{\text {corr }}\right)$, anodic and cathodic Tafel slopes, and linear polarisation resistance are listed in Table 5.
Inhibition efficiency (\% IE) values were calculated from current density $\left(i_{\text {corr }}\right)$ using the Tafel plot

$$
\% \mathrm{IE}=\frac{i_{\text {corr }}^{o}-i_{\text {corr }}}{i_{\text {corr }}^{o}} \times 100 \text {, }
$$

where $i_{\text {corr }}^{o}$ and $i_{\text {corr }}$ are the uninhibited and the inhibited corrosion current densities, respectively. The corrosion current density for blank is $0.2 \mathrm{~mA} \mathrm{~cm}^{-2}$ which decreases after the addition of inhibitors. This confirms that inhibitor acts as an obstacle which prevents the corrosion attack.

As shown in Figure 6, both cathodic and anodic corrosion reactions of MS were inhibited with the increase of inhibitor concentration in $0.5 \mathrm{M} \mathrm{HCl}$ solutions. The anodic currentpotential curves give rise to parallel Tafel lines, which indicate that the studied Schiff bases do not modify the mechanism of steel dissolution process. Additive inhibitors caused positive shift in corrosion potential. Even though both reactions are suppressed after the addition of inhibitor, anodic reaction is predominantly suppressed. This can be established further by anodic and cathodic Tafel slope values. After the addition of inhibitors, both anodic and cathodic Tafel slopes show shift from blank value and considerable shift is shown by anodic Tafel slope. According to Ferreira et al. [35] the displacement in $E_{\text {corr }}$ is more than $\pm 85 \mathrm{mV}$ relating to the corrosion potential of the blank; the inhibitor can be considered as of cathodic or anodic type. If the change in $E_{\text {corr }}$ is less than $\pm 85 \mathrm{mV}$, the corrosion inhibitor may be regarded as of mixed type. For the studied inhibitors 2-MTPH, 3-MTPH, and 4MTPH maximum change in $E_{\text {corr }}$ is $39 \mathrm{mV}, 29 \mathrm{mV}$, and $36 \mathrm{mV}$, respectively, so none of the studied inhibitors is wholly anodic or cathodic but all are of mixed type. Schmid and Huang [36] found that organic molecules inhibit both the anodic and cathodic partial reactions on the electrode surface and a parallel reaction takes place on the covered area, but the reaction rate on the covered area is substantially less than 


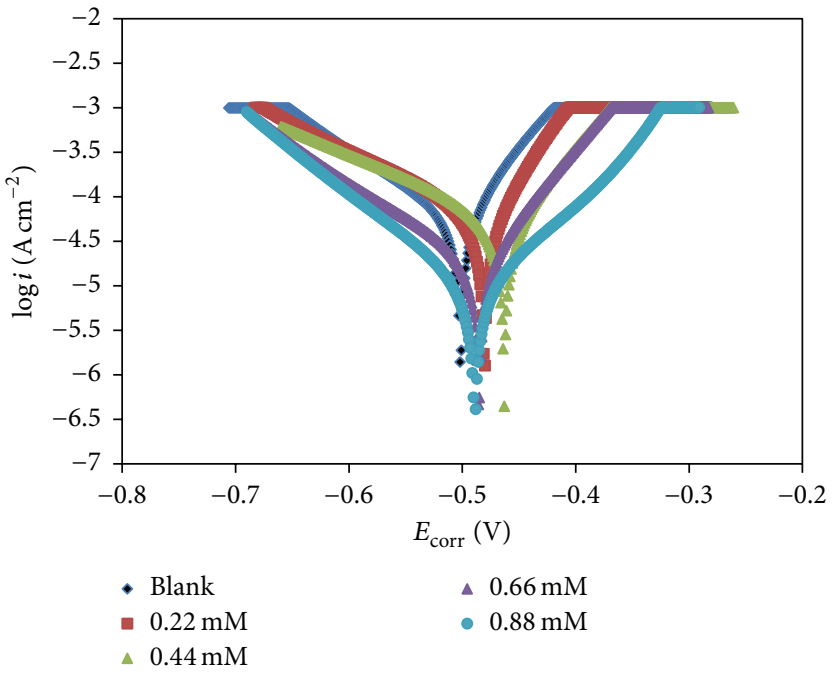

(a)

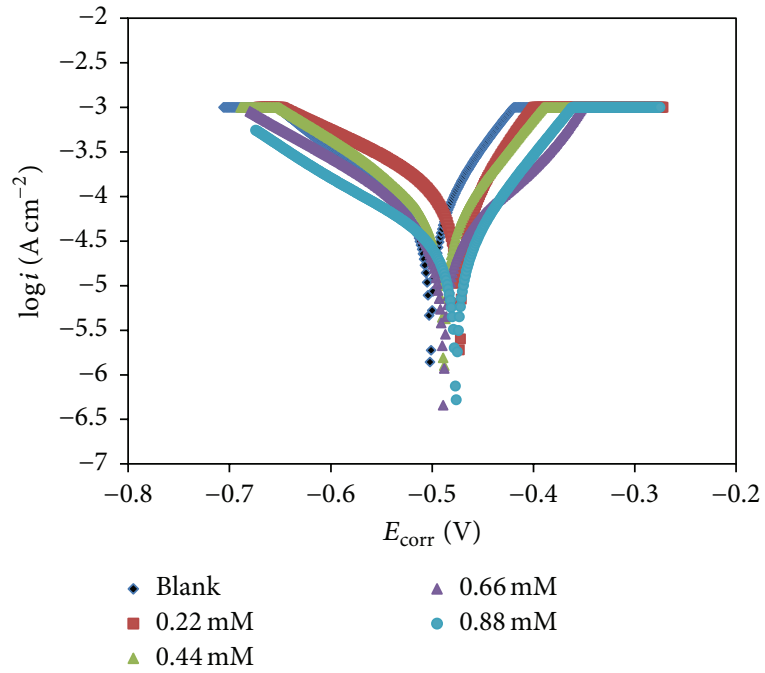

(b)

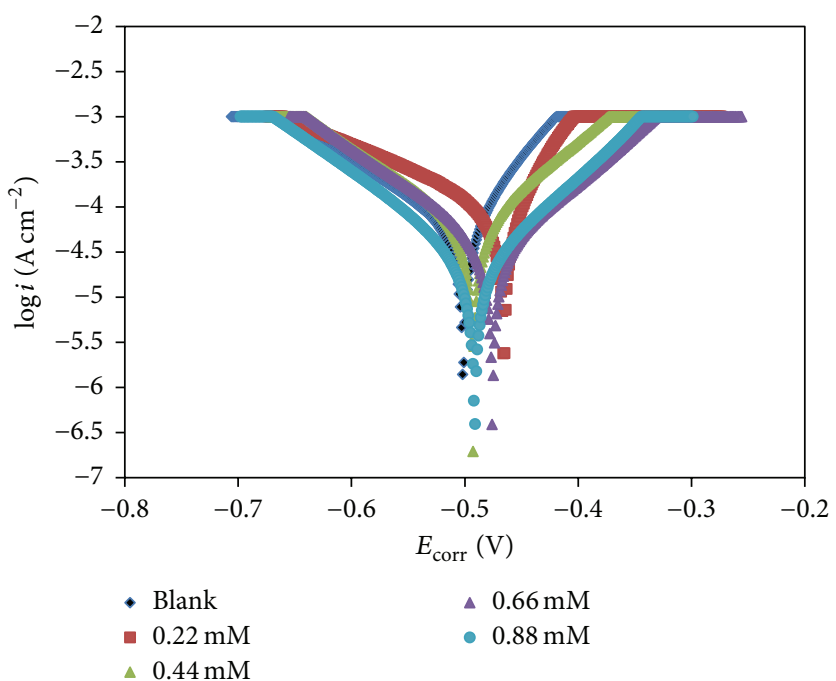

(c)

FIGURE 6: Tafel plots for MS in $0.5 \mathrm{M} \mathrm{HCl}$ containing different concentration of (a) 2-MTPH, (b) 3-MTPH, and (c) 4-MTPH.

TABLE 5: Potentiodynamic polarization parameters for the corrosion of $\mathrm{MS}$ in $0.5 \mathrm{M} \mathrm{HCl}$ in the absence and presence of different concentrations of 2-MTPH, 3-MTPH, and 4-MTPH at $303 \mathrm{~K}$.

\begin{tabular}{|c|c|c|c|c|c|c|c|}
\hline Inhibitor & Concentration & $E_{\text {corr }}(\mathrm{mV})$ & $i_{\text {corr }}\left(\mathrm{mA} \mathrm{cm}^{-2}\right)$ & $b_{a}\left(\mathrm{mV} \mathrm{dec}^{-1}\right)$ & $b_{c}\left(\mathrm{mV} \mathrm{dec}{ }^{-1}\right)$ & Linear polarisation & \% IE \\
\hline & Blank & -502 & 0.2 & 4.53 & 2.65 & 302 & - \\
\hline \multirow{4}{*}{ 2-МТРН } & 0.22 & -480 & 0.0630 & 15.24 & 6.03 & 324 & 68.5 \\
\hline & 0.44 & -463 & 0.0544 & 13.25 & 5.64 & 422 & 72.8 \\
\hline & 0.66 & -486 & 0.0198 & 14.86 & 7.76 & 970 & 90.1 \\
\hline & 0.88 & -489 & 0.0099 & 11.86 & 9.50 & 2057 & 95.1 \\
\hline \multirow{4}{*}{ 3-МТРН } & 0.22 & -476 & 0.107 & 12.30 & 5.86 & 224 & 46.5 \\
\hline & 0.44 & -489 & 0.0797 & 9.54 & 6.15 & 374 & 60.2 \\
\hline & 0.66 & -488 & 0.0428 & 8.94 & 7.15 & 610 & 77.9 \\
\hline & 0.88 & -473 & 0.0271 & 13.96 & 6.51 & 782 & 86.4 \\
\hline \multirow{4}{*}{ 4-МТPH } & 0.22 & -466 & 0.1007 & 15.05 & 5.58 & 295 & 49.7 \\
\hline & 0.44 & -493 & 0.0718 & 10.15 & 8.21 & 422 & 64.1 \\
\hline & 0.66 & -476 & 0.0423 & 9.69 & 8.42 & 674 & 78.9 \\
\hline & 0.88 & -491 & 0.0243 & 10.60 & 9.34 & 896 & 87.8 \\
\hline
\end{tabular}




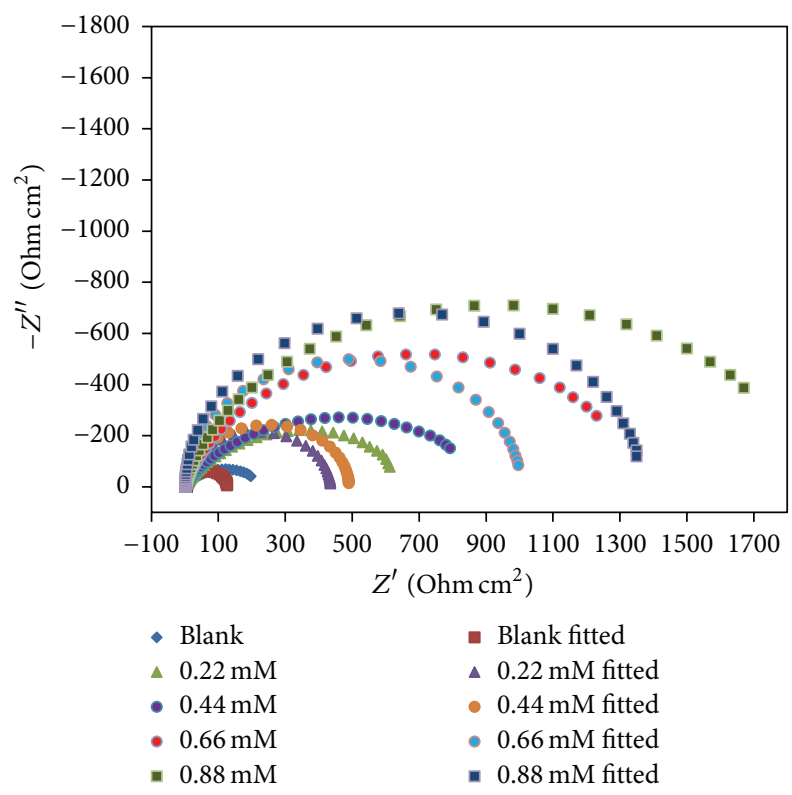

(a)

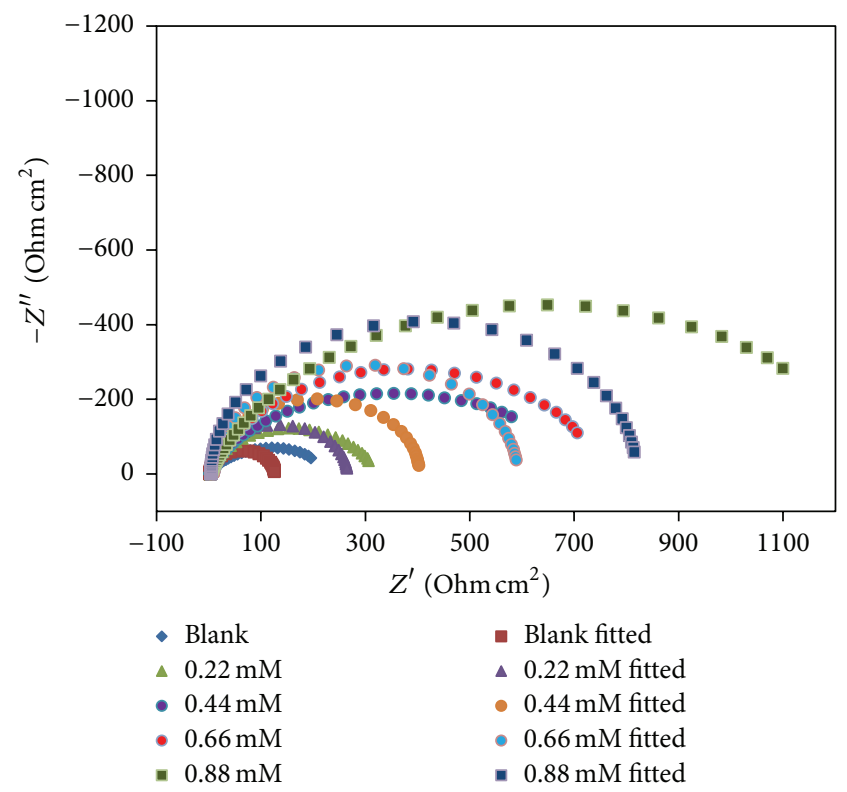

(b)

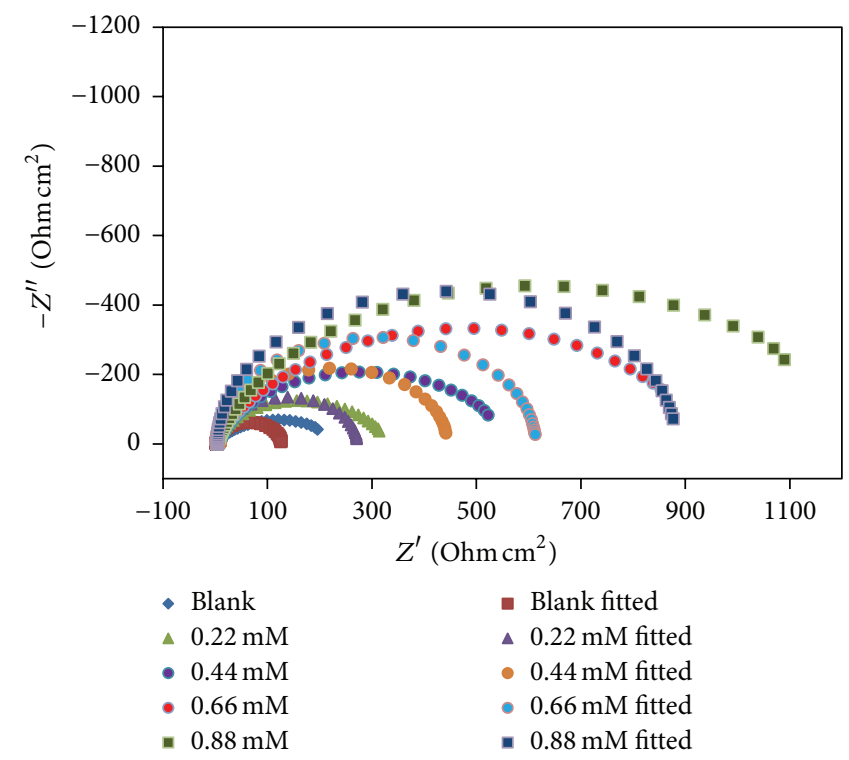

(c)

Figure 7: Nyquist plots (experimental and fitted) in the absence and presence of different concentrations of (a) 2-MTPH, (b) 3-MTPH, and (c) 4-MTPH.

on the uncovered area. So corrosion of MS can be vanished completely, but the added inhibitor moieties are effectively preventing exposure of more anodic and cathodic surface area there by exhibiting good inhibition efficiency. Linear polarisation resistance (LPR) for blank is $302 \Omega \mathrm{cm}^{2}$ which is less compared to LPR for all studied inhibitors at all studied concentrations. LPR increases with additive concentration of all three inhibitors.

3.3. Electrochemical Impedance Spectroscopy. As the weight loss and potentiodynamic polarisation methods produced good results, further, EIS methods were carried out. The corrosion reaction is strictly charge transfer controlled, and its behavior can be explained by simple and commonly used circuit consisting of charge transfer resistance $\left(R_{\mathrm{ct}}\right)$, solution resistance $\left(R_{s}\right)$, and double layer capacitance $\left(C_{\mathrm{dl}}\right)$. The double layer capacitance is in parallel with the impedance due to charge transfer reaction [37]. This method permits superimposing a small sinusoidal excitation to an applied potential and then the electrochemical metal-solution interface offers impedance [38]. From the impedance data metalsolution interface behavior can be explained by making use of equivalent circuit models (Figure 8).

Impedance parameters $R_{s}, R_{\mathrm{ct}}$, and $C_{\mathrm{dl}}$ for 2-MTPH, 3$\mathrm{MTPH}$, and $4-\mathrm{MTPH}$ in $0.5 \mathrm{M} \mathrm{HCl}$ are listed in Table 6. Nyquist plots in the form of semicircles are shown in Figure 7. 


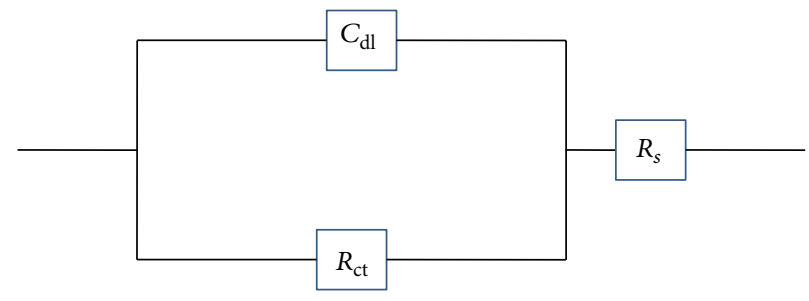

Figure 8: Equivalent circuit model.

TABLE 6: Impedance parameters for the corrosion of $\mathrm{MS}$ in $0.5 \mathrm{M} \mathrm{HCl}$ in the absence and presence of different concentrations of inhibitors at $303 \mathrm{~K}$.

\begin{tabular}{|c|c|c|c|c|c|}
\hline Inhibitor & Concentration $(\mathrm{mM})$ & $R_{\mathrm{ct}}\left(\mathrm{Ohm} \mathrm{cm}^{2}\right)$ & $C_{\mathrm{dl}}\left(\mu \mathrm{F} \mathrm{cm}^{-2}\right)$ & $R_{s}\left(\mathrm{Ohm} \mathrm{cm}^{2}\right)$ & $\% \mathrm{IE}$ \\
\hline & Blank & 124 & 59.7 & 2.84 & - \\
\hline \multirow{4}{*}{ 2-MTPH } & 0.22 & 393 & 33.1 & 8.10 & 68.5 \\
\hline & 0.44 & 486 & 25.9 & 3.40 & 74.6 \\
\hline & 0.66 & 998 & 25.6 & 4.66 & 87.6 \\
\hline & 0.88 & 1360 & 14.9 & 1.32 & 91.0 \\
\hline \multirow{4}{*}{ 3-МТPH } & 0.22 & 262 & 33.7 & 3.72 & 52.8 \\
\hline & 0.44 & 400 & 21.9 & 3.91 & 69.1 \\
\hline & 0.66 & 581 & 17.5 & 9.58 & 78.7 \\
\hline & 0.88 & 815 & 14.0 & 4.68 & 84.8 \\
\hline \multirow{4}{*}{ 4-МТРН } & 0.22 & 268 & 39.9 & 3.74 & 53.9 \\
\hline & 0.44 & 435 & 14.1 & 9.89 & 71.6 \\
\hline & 0.66 & 610 & 13.5 & 5.07 & 79.7 \\
\hline & 0.88 & 886 & 10.3 & 4.54 & 86.1 \\
\hline
\end{tabular}

The shape of the curve is retained even after the addition of inhibitor indicating that the mechanism of the anodic and cathodic processes remains unaltered. As there is no frequency dispersion in the semicircles, the adsorption can be considered homogeneous which supports Langmuir kind of adsorption obtained previously.

To get the double layer capacitance $\left(C_{\mathrm{dl}}\right)$, the frequency at which the imaginary component of the impedance is maximal $\left(Z_{\max }\right)$ is found as represented in the following equations:

$$
\begin{aligned}
C_{\mathrm{dl}} & =\frac{1}{\omega R_{\mathrm{ct}}}, \\
\omega & =2 \pi f_{\max } .
\end{aligned}
$$

Double layer capacitance for blank is $59.7 \mu \mathrm{F} \mathrm{cm}^{-2}$ and decreases to lower value with additive concentration of inhibitors and reaches minimum in optimum concentration of the inhibitor. The decrease in capacitance is caused by loss of deposited charge on the MS surface. The two predicted reasons for the reduction in charge from double layer are (i) formation of film due to the adsorption of inhibitor on the steel surface which disturbs the double layer and (ii) desorption of water molecules from the steel surface resulting in decrease in local dielectric constant.

Charge transfer resistance $\left(R_{\mathrm{ct}}\right)$ value is a measure of electron transfer across the surface and is inversely proportional to corrosion rate. The charge transfer resistance value $\left(R_{\mathrm{ct}}\right)$ is calculated from the difference in real impedance at lower and higher frequencies reported by Tsuru et al. [39]. Inhibition efficiency can be calculated by $R_{\mathrm{ct}}$ using

$$
\% \mathrm{IE}=\frac{\left(R_{\mathrm{ct}}\right)_{p}-\left(R_{\mathrm{ct}}\right)_{a}}{\left(R_{\mathrm{ct}}\right)_{p}} \times 100,
$$

where $\left(R_{\mathrm{ct}}\right)_{a}$ and $\left(R_{\mathrm{ct}}\right)_{p}$ are the charge transfer resistance in the absence and presence of inhibitor, respectively. $R_{\mathrm{ct}}$ values obtained for three inhibitors 2-MTPH, 3-MTPH, and 4-MTPH are higher compared to $R_{\mathrm{ct}}$ in the absence of inhibitors. This indicates that the film formed by the inhibitor acts as a barrier and suppresses the electron transfer resulting in high resistance value.

Bode plots were recorded for $\mathrm{MS}$ in $0.5 \mathrm{M} \mathrm{HCl}$ in the absence and presence of all the inhibitors (Figure 9). As the concentration of the inhibitor increases, there is shift in phase angle. The broadening of the peak is the result of protective layer formed on the MS surface. There is only one-phase maximum in bode plot for all three inhibitors, indicating only one relaxation process, which would be the charge transfer process, taking place at the metal-electrolyte interface.

3.4. Mechanism of Inhibition. Inhibition mechanism can be explained through different kinds of adsorption phenomena. As all three inhibitors 2-MTPH, 3-MTPH, and 4-MTPH 

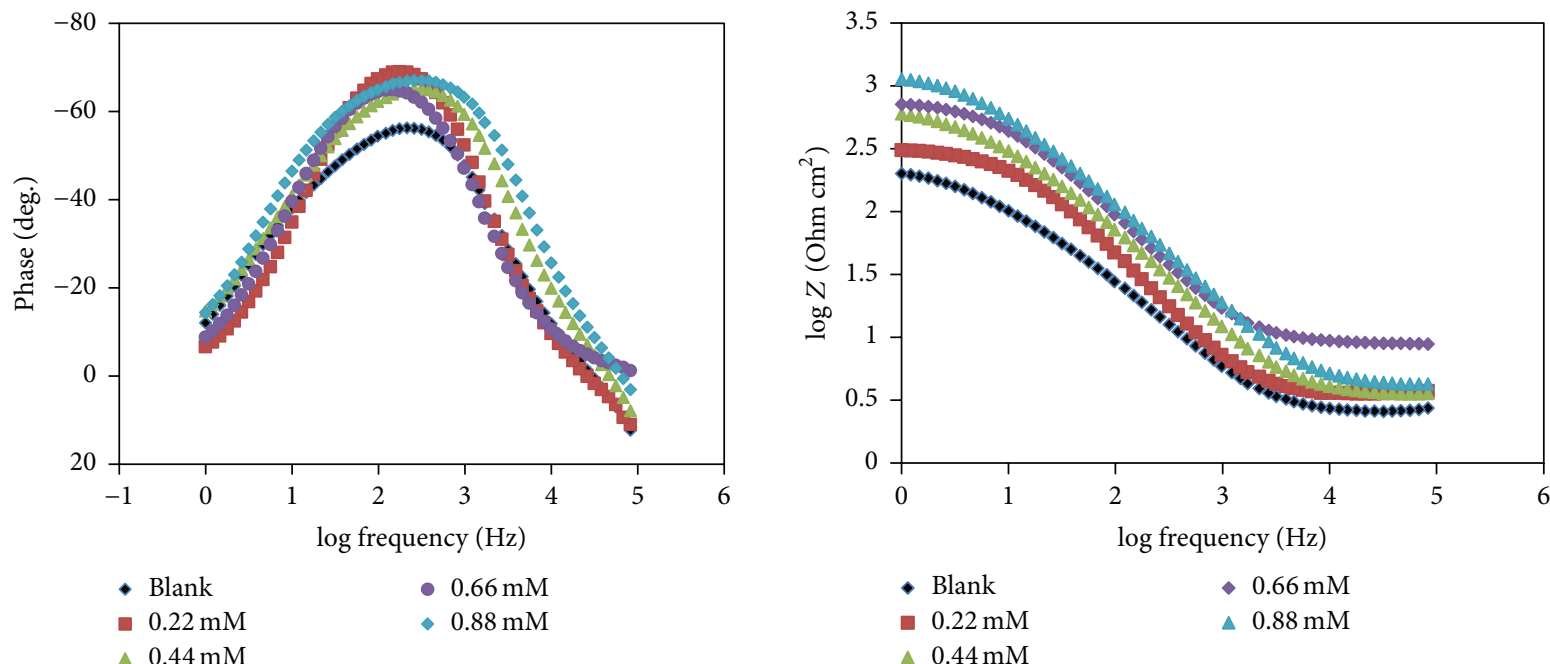

(a)
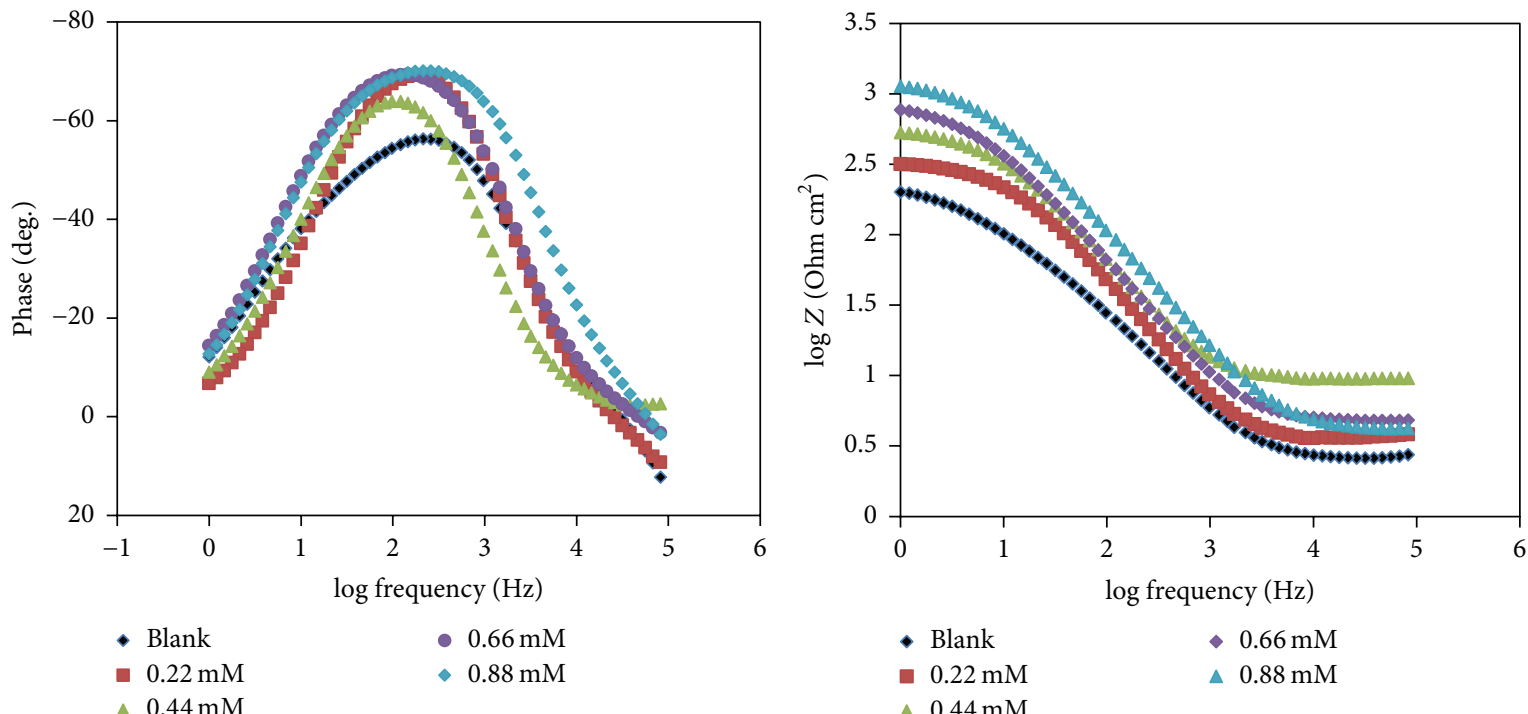

(b)
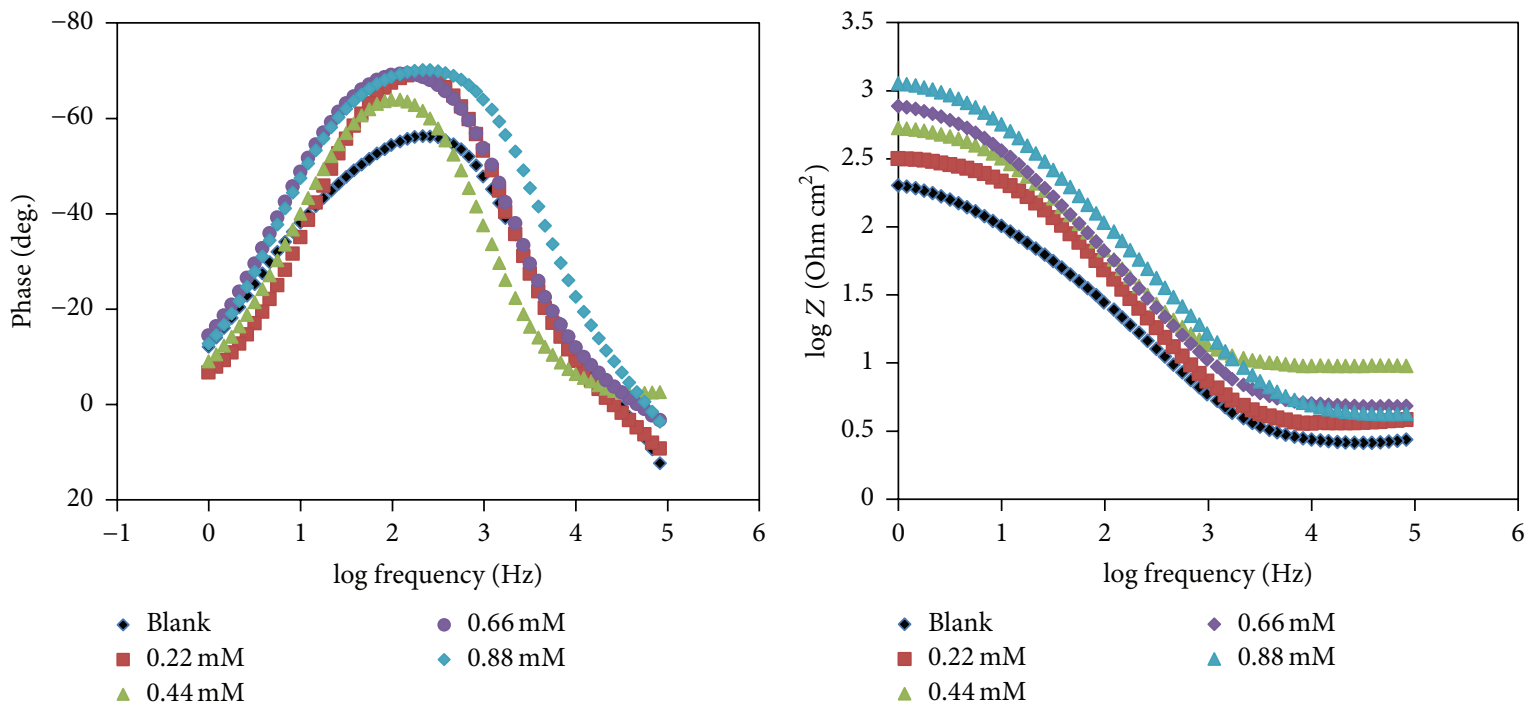

(c)

FIGURE 9: Bode plots in the absence and presence of different concentrations of (a) 2-MTPH, (b) 3-MTPH, and (c) 4-MTPH. 


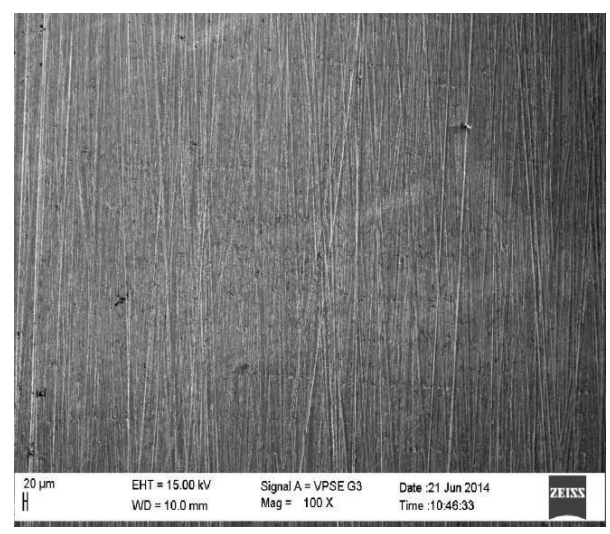

(a)

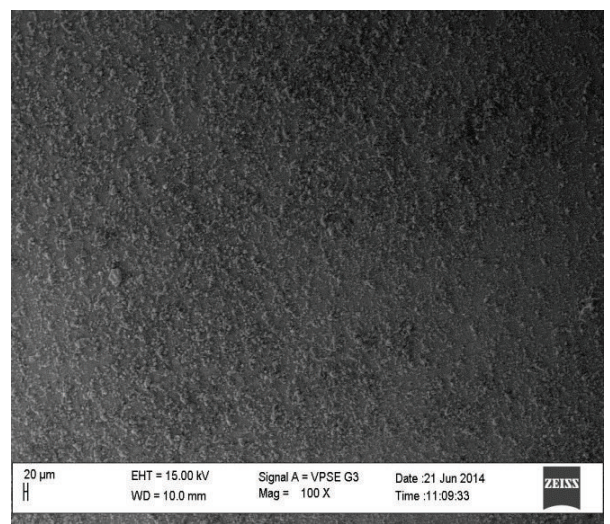

(c)

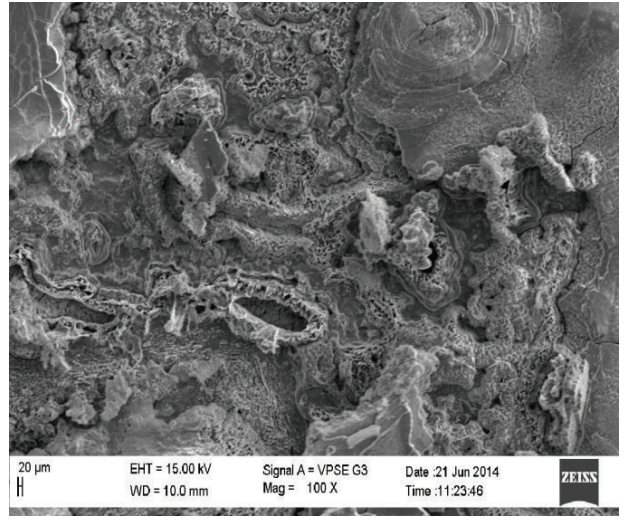

(b)

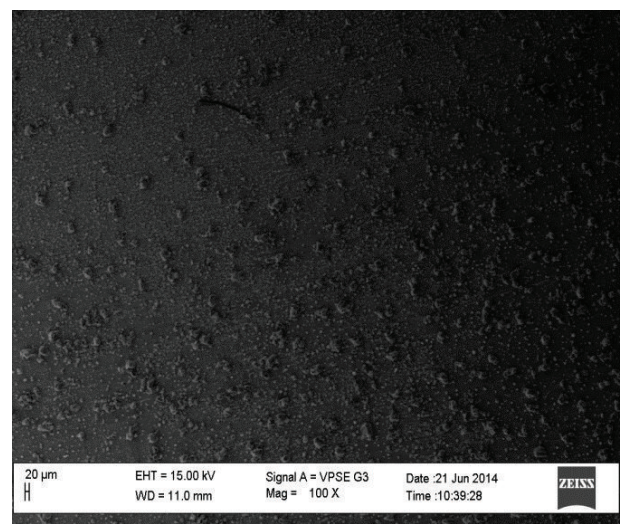

(d)

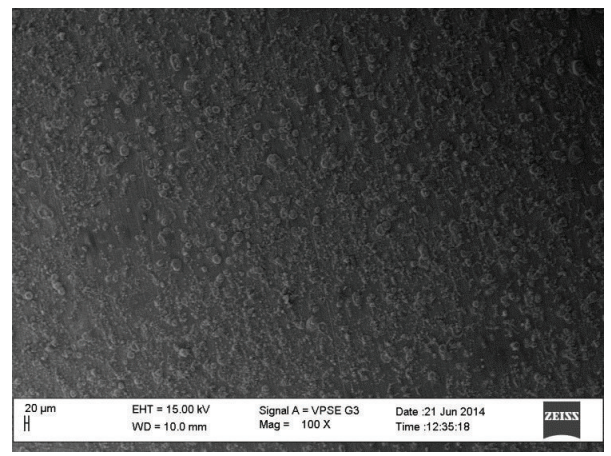

(e)

Figure 10: SEM images of MS surface (a) polished, (b) immersed in $0.5 \mathrm{M} \mathrm{HCl}$, (c) immersed in $0.5 \mathrm{M} \mathrm{HCl}$ in the presence of 2-MTPH, (d) immersed in $0.5 \mathrm{M} \mathrm{HCl}$ in the presence of 3-MTPH, and (e) immersed in $0.5 \mathrm{M} \mathrm{HCl}$ in the presence of 4-MTPH.

possess nitrogen atom, they can be protonated easily. In acidic solution, both neutral and cationic forms of inhibitors exist. It is assumed that $\mathrm{Cl}^{-}$ion first got adsorbed onto the positively charged metal surface by columbic attraction and then cationic form of inhibitor molecules can be adsorbed through electrostatic interactions between the positively charged molecules and the negatively charged metal surface [40]. That is protonated form of Schiff bases that binds to $\left(\mathrm{FeCl}^{-}\right)$species by physical kind of adsorption [41]. Chemisorption can occur by either the coordinate bond formed between vacant d-orbitals of iron and lone pair of electrons on heteroatoms ( $\mathrm{N}$ and $\mathrm{S}$ ) of thiazole and pyridine rings or $\pi$ electrons of imide bond and aromatic rings. Also, the presence of electron donating- $\mathrm{OCH}_{3}$ group helps in increasing electron density on benzene ring.

3.5. Scanning Electron Microscope (SEM). The SEM micrographs obtained for MS surface in the absence and presence of optimum concentration $(0.88 \mathrm{mM})$ of the inhibitors in $0.5 \mathrm{M}$ $\mathrm{HCl}$ after $4 \mathrm{~h}$ of immersion at $30^{\circ} \mathrm{C}$ are shown in Figures 10(a)-10(e). The polished MS surface is smooth without pits 


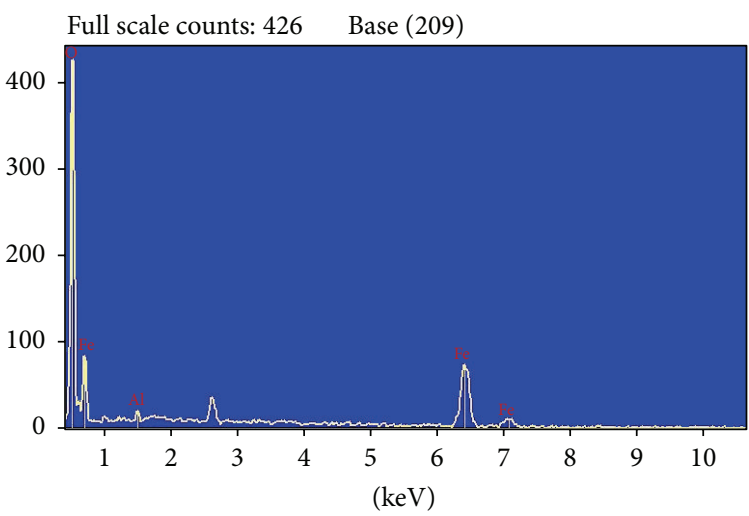

(a)

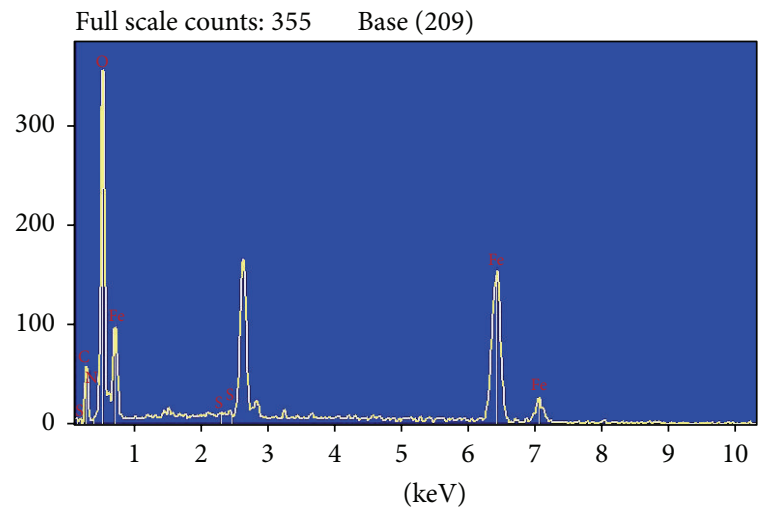

(c)

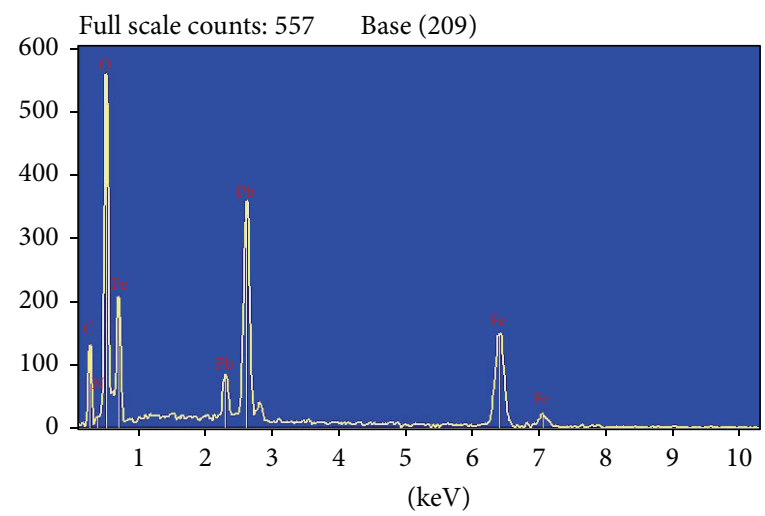

(b)

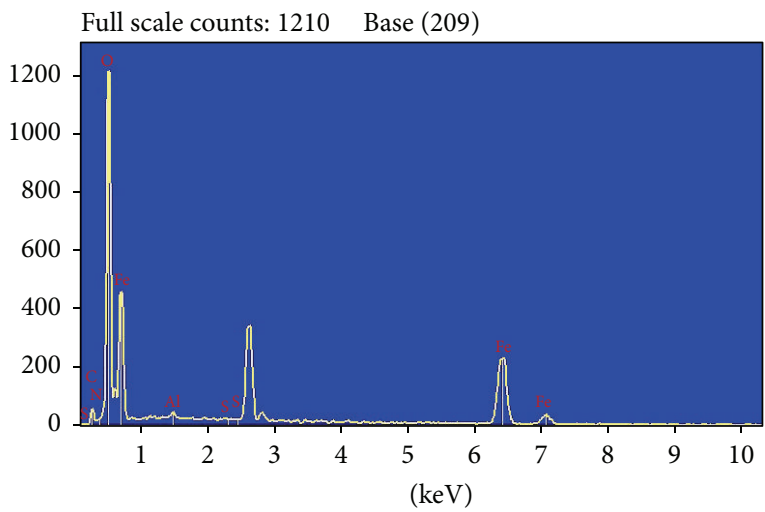

(d)

Figure 11: EDX spectra of MS in (a) $0.5 \mathrm{M} \mathrm{HCl}$, (b) $0.88 \mathrm{mM}$ of 2-MTPH, (c) $0.88 \mathrm{mM}$ of 3-MTPH, and (d) $0.88 \mathrm{mM}$ of 4-MTPH.

and cracks. When the MS surface is exposed to $0.5 \mathrm{M} \mathrm{HCl}$ without inhibitor, the surface gets highly damaged which consists of pits and cracks. But, when the MS surface is exposed to optimum concentration of 2-MTPH, 3-MTPH, and 4-MTPH there is a formation of stable protective layer on the steel surface which suppresses the charge and mass transfer by acting as a barrier, so the surface shows enhanced properties.

3.6. Energy Dispersive X-Ray Analysis (EDX). Energy dispersive X-ray analysis is employed to get compositional information of the surface of the MS sample in $0.5 \mathrm{M} \mathrm{HCl}$ in the absence and presence of inhibitors. The EDX spectra obtained for three inhibitors are shown in Figures 11(a)11(d). The percentage atomic content of the uninhibited and inhibited MS samples is mentioned in Table 7. There is a considerable decrease in percentage of atomic content of Fe after the addition of inhibitors. When measured for MS surface immersed in $0.5 \mathrm{M} \mathrm{HCl}$, the atomic content of iron was around $56.95 \%$ but decreases to $10.30 \%, 17.83 \%$, and $12.61 \%$ for optimum concentration $(0.88 \mathrm{mM})$ of $2-\mathrm{MTPH}$, 3-MTPH, and 4-MTPH, respectively. The suppression in the $\mathrm{Fe}$ lines is due to formation of inhibitory film on the MS and maximum suppression is shown by $2-\mathrm{MTPH}$. The peaks corresponding to other elements such as nitrogen, oxygen, carbon, and oxygen are also present in inhibited EDX spectra.

3.7. FTIR Spectral Analysis. The FTIR spectra of all three inhibitors without and with adsorption on the MS are given in Figures 12(a)-12(f). After adsorption to the MS there are many changes in the FTIR spectra of all three inhibitors. In 2-MTPH, the $\mathrm{C}=\mathrm{N}$ peak which appears at $1609 \mathrm{~cm}^{-1}$ has disappeared. The $\mathrm{C}=\mathrm{O}$ peak which appears at $1684 \mathrm{~cm}^{-1}$ has been shifted to $1625 \mathrm{~cm}^{-1}$ with reduced intensity. The N-H peak which appears at $3114 \mathrm{~cm}^{-1}$ has been broadened with increased intensity and shifted to $3192 \mathrm{~cm}^{-1}$. The $\mathrm{C}-\mathrm{H}$ peak of $-\mathrm{OCH}_{3}$ group appears with reduced intensity. Series of peaks of $\mathrm{C}=\mathrm{C}$ vibration between $1465 \mathrm{~cm}^{-1}$ and $1585 \mathrm{~cm}^{-1}$ become very less intense. In 3-MTPH, the $1606 \mathrm{~cm}^{-1}$ peak of $\mathrm{C}=\mathrm{N}$ has been shifted to $1617 \mathrm{~cm}^{-1}$ with broadening. The $\mathrm{C}=\mathrm{O}$ peak which appears at $1657 \mathrm{~cm}^{-1}$ has disappeared. The N-H peak which appears at $3241 \mathrm{~cm}^{-1}$ has been shifted to $3232 \mathrm{~cm}^{-1}$. The $\mathrm{C}-\mathrm{H}$ peak of $-\mathrm{OCH}_{3}$ group appears with reduced intensity. Series of peaks between $1480 \mathrm{~cm}^{-1}$ and $1589 \mathrm{~cm}^{-1}$ corresponds to $\mathrm{C}=\mathrm{C}$ that appears with very low intensity. In $4-\mathrm{MTPH}$ the $\mathrm{C}=\mathrm{N}$ peak which appears at $1607 \mathrm{~cm}^{-1}$ has been shifted to $1609 \mathrm{~cm}^{-1}$ with increased intensity. The $\mathrm{C}=\mathrm{O}$ peak which appears at $1660 \mathrm{~cm}^{-1}$ shifts to $1672 \mathrm{~cm}^{-1}$. The $\mathrm{N}-\mathrm{H}$ peak which appears at $3246 \mathrm{~cm}^{-1}$ has been shifted 


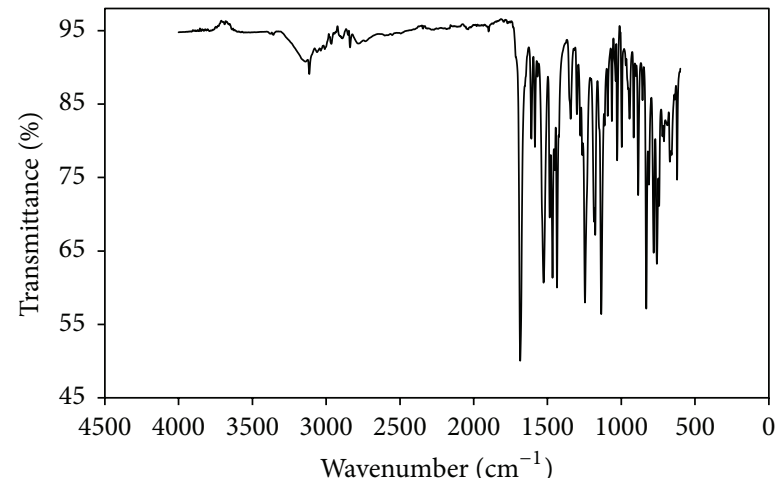

(a)

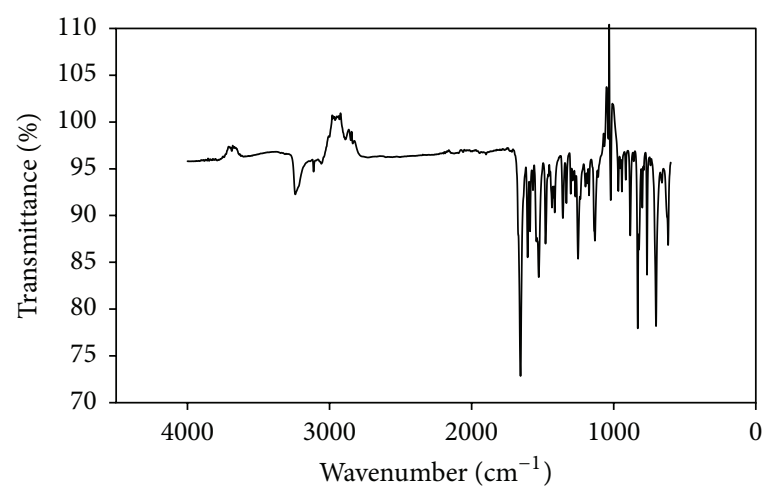

(c)

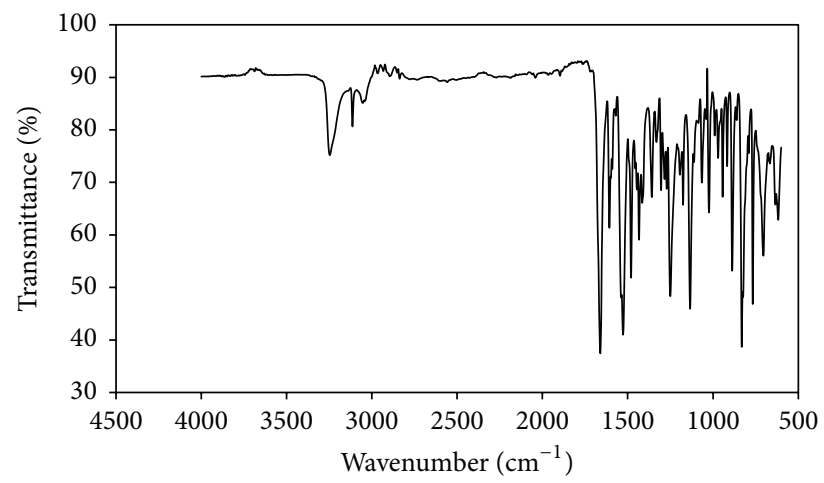

(e)

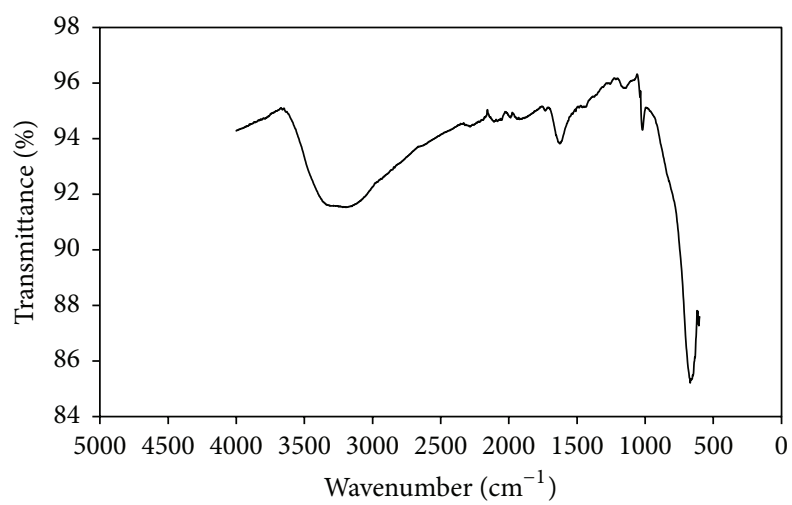

(b)

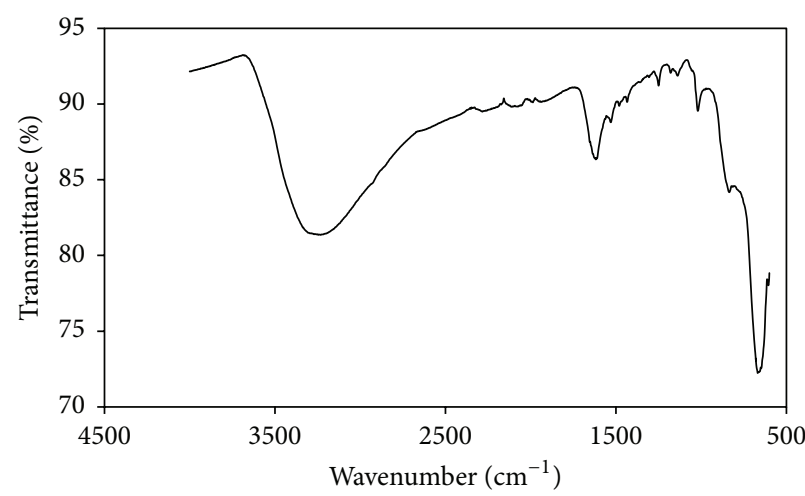

(d)

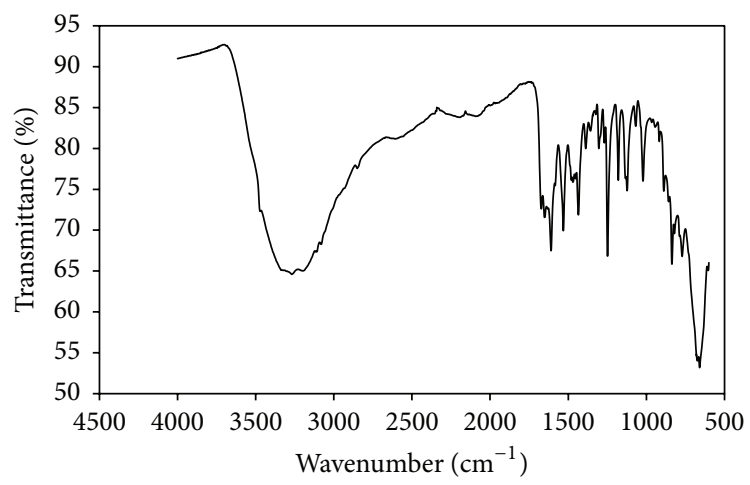

(f)

FIGURE 12: FITR spectra of (a) pure 2-MTPH, (b) scratched MS surface adsorbed 2-MTPH film, (c) pure 3-MTPH, (d) scratched MS surface adsorbed 3-MTPH film, (e) pure 4-MTPH, and (f) scratched MS surface adsorbed 4-MTPH.

to $3269 \mathrm{~cm}^{-1}$. The $\mathrm{C}-\mathrm{H}$ peak of $-\mathrm{OCH}_{3}$ group appears at $1434 \mathrm{~cm}^{-1}$ instead of $1446 \mathrm{~cm}^{-1}$. Series of peaks which appear at $1480-1590 \mathrm{~cm}^{-1}$ become very less intense. The changes in the absorption pattern of these bands confirm the involvement of bonds in the adsorption of inhibitor to the steel surface.

3.8. Quantum Chemical Calculations. Quantum chemical method provides an insight into the mechanism of inhibitor adsorption on the MS surface. Particularly, for the molecules exhibiting close resemblance it is a very useful tool to establish relation between structure and activity. Present study aims to determine the corrosion inhibition performance of isomeric pyridine derivatives. So, chemical and electrochemical methods coupled with quantum chemical methods can be used as a systematic approach for the proper selection of inhibitor. It has been found that the effectiveness of a corrosion inhibitor can be related to its electronic and spatial molecular structure [42, 43]. Organic compounds which can donate electrons to unoccupied dorbitals of metal surface to form coordinate covalent bonds and can also accept free electrons from the metal surface by using their antibonding orbitals to form feedback bonds constitute excellent corrosion inhibitors [44]. The study 
TABLE 7: Percentage of atomic contents of elements obtained from EDX spectra.

\begin{tabular}{|c|c|c|c|c|c|c|c|}
\hline \multirow{2}{*}{ Mild steel surface under investigation } & \multicolumn{7}{|c|}{ Percentage of elements detected } \\
\hline & $\mathrm{Fe}$ & $\mathrm{C}$ & $\mathrm{O}$ & $\mathrm{N}$ & S & $\mathrm{Al}$ & $\mathrm{Pb}$ \\
\hline Immersed in $0.5 \mathrm{~N} \mathrm{HCl}$ & 57.0 & - & 41.6 & - & - & 1.46 & - \\
\hline Immersed in $8.8 \mathrm{mM}$ of $2-\mathrm{MTPH}$ & 10.3 & 17.0 & 43.0 & 29.1 & - & - & 0.66 \\
\hline Immersed in $8.8 \mathrm{mM}$ of $3-\mathrm{MTPH}$ & 17.9 & 15.8 & 40.3 & 26.0 & 0.10 & - & - \\
\hline Immersed in $8.8 \mathrm{mM}$ of $4-\mathrm{MTPH}$ & 12.6 & 12.4 & 51.1 & 23.3 & 0.36 & 0.19 & - \\
\hline
\end{tabular}

TABLE 8: List of quantum chemical parameters.

\begin{tabular}{lccc}
\hline Quantum chemical parameters & 2-MTPH & 3-MTPH & 4-MTPH \\
\hline$E_{\mathrm{HOMO}}(\mathrm{eV})$ & 9.690 & -7.7998 & -7.7473 \\
$E_{\mathrm{LUMO}}(\mathrm{eV})$ & 10.087 & 2.165 & 2.119 \\
$\Delta E=E_{\mathrm{LUMO}}-E_{\mathrm{HOMO}}(\mathrm{eV})$ & 0.3971 & 9.9647 & 9.8473 \\
Dipole moment $($ debyes $)$ & 3.2405 & 3.0251 & 3.2778 \\
Ionisation potential $I=-E_{\mathrm{HOMO}}$ & -9.690 & 7.998 & 7.8475 \\
Hardness of the molecule $(\eta)$ & 0.3971 & 4.9823 & 4.9831 \\
Softness $(\sigma)$ & 2.5178 & 0.2007 & 0.2006 \\
\hline
\end{tabular}

of various quantum chemical parameters such as $E_{\mathrm{HOMO}}$ (energy of highest occupied molecular orbital), $E_{\mathrm{LUMO}}$ (energy of lowest unoccupied molecular orbital), $\Delta E$ (energy gap), $\mu$ (dipole moment), ionisation potential $(I)$, electron affinity $(A)$, electronegativity $(\chi)$, hardness $(\eta)$, and softness $(\sigma)$ (Table 8) gives valuable information about electronic structure, energy of different orbitals, and electron density of the molecule, thus helping to construct composite index of an inhibitor. Quantum chemical structures are given in Table 9.

According to the Frontier molecular orbital theory (FMO) of chemical reactivity, transition of an electron is due to interaction between highest occupied molecular orbital (HOMO) and lowest unoccupied molecular orbital (LUMO) of reacting species [45]. Terms involving the frontier MO could provide the predominant contribution, because of the inverse dependence of stabilization energy on orbital energy difference [46]. $E_{\mathrm{HOMO}}$ is often associated with the electron donating ability of a molecule. Therefore, higher value of $E_{\mathrm{HOMO}}$ ensures higher tendency for the donation of electron(s) to the appropriate acceptor molecule with lowenergy and empty molecular orbital [47]. Among the studied inhibitors the highest value of $E_{\mathrm{HOMO}}$ is exhibited by 2MTPH, so it can donate electrons easily and emerges as the most efficient inhibitor among three studied inhibitors. Lower values of energy gap $(\Delta E)$ will render good inhibition efficiency, because the energy to remove the last occupied orbital will be low [48]. The $\Delta E$ values obtained follow the order $2-\mathrm{MTPH}<4-\mathrm{MTPH}<3-\mathrm{MTPH}$, so inhibition efficiency follows the reverse order. The calculated values are in good correlation with the experimental results and thus validate them. Ionisation potential describes the chemical reactivity of a molecule. The higher the value of ionisation potential, the more stable the molecule. Among the studied inhibitors, 2-MTPH has the least value of ionisation potential. So it is a better donor of electrons and exhibits highest efficiency. The " $\mu$ " values obtained are inconsistent on the use of dipole moment as a predictor for the direction of a corrosion inhibition reaction. Also there is a lack of agreement in the literature on the correlation between the dipole moment and inhibition efficiency $[49,50]$.

Hardness and softness are the important criteria to measure the reactivity of the molecules. According to HSAB concept hard acids tend to react with hard bases and soft acids actively react with soft bases. Chemical hardness can be explained as the opposition towards the polarisation of an electron cloud under small perturbation in chemical reaction. Soft molecule is the one with a low energy gap that is more polarisable and generally associated with the high chemical reactivity and low kinetic stability [51]. As Fe is a soft acid it interacts more with soft base such as 2-MTPH (highest value of softness and lowest value of hardness) compared to other two molecules. So 2-MTPH adsorbs more firmly to the steel surface.

\section{Conclusion}

(i) Thiazole based pyridine derivatives emerge as very good inhibitors against MS corrosion in $0.5 \mathrm{M} \mathrm{HCl}$ medium and inhibition efficiency follows the order 2$\mathrm{MTPH}>4$-MTPH > 3-MTPH.

(ii) Corrosion rate decreases with increase in concentration of the inhibitor and increases with increase in temperature of the medium.

(iii) The adsorption of all the inhibitors follows Langmuir isotherm. 
TABLE 9: List of quantum chemical structures.
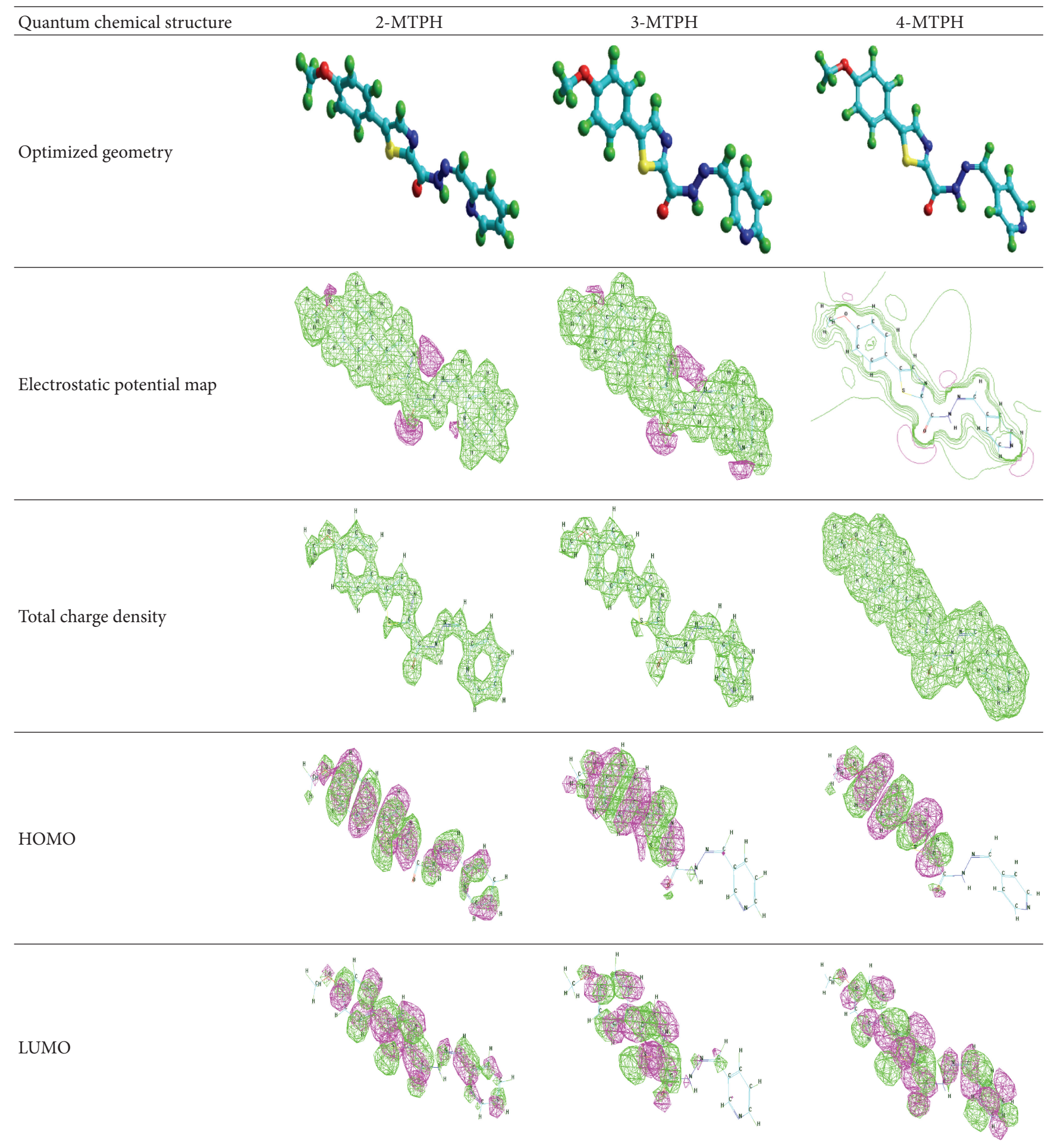

(iv) Polarisation study reveals that the inhibitors affect both cathodic and anodic reactions but predominantly anodic ones.

(v) EIS study shows that charge transfer resistance increases and double layer capacitance decreases as the concentration of the inhibitor increases. (vi) Morphological study (SEM and EDX) confirms the presence of protective inhibitory film on MS surface.

(vii) Quantum chemical study is reasonably in good agreement with experimental results. 


\section{Conflict of Interests}

The authors declare that there is no conflict of interests regarding the publication of this paper.

\section{Acknowledgment}

One of the authors (T. K. Chaitra) received NON-NET Fellowship from University of Mysore, Mysore, and it is gratefully acknowledged.

\section{References}

[1] D. D. N. Singh, T. B. Singh, and B. Gaur, "The role of metal cations in improving the inhibitive performance of hexamine on the corrosion of steel in hydrochloric acid solution," Corrosion Science, vol. 37, no. 6, pp. 1005-1019, 1995.

[2] G. Trabanelli, "Inhibitors-an old remedy for a new challenge," Corrosion, vol. 47, no. 6, pp. 410-419, 1991.

[3] M. A. Chidiebere, E. E. Oguzie, L. Liu, Y. Li, and F. Wang, "Corrosion inhibition of Q235 mild steel in $0.5 \mathrm{M} \mathrm{H}_{2} \mathrm{SO}_{4}$ solution by phytic acid and synergistic iodide additives," Industrial and Engineering Chemistry Research, vol. 53, no. 18, pp. 7670-7679, 2014.

[4] M. Bouklah, A. Attayibat, B. Hammouti, A. Ramdani, S. Radi, and M. Benkaddour, "Pyridine-pyrazole compound as inhibitor for steel in $1 \mathrm{M} \mathrm{HCl}$," Applied Surface Science, vol. 240, no. 1-4, pp. 341-348, 2005.

[5] A. Ghazoui, R. Saddik, N. Benchat et al., "The role of 3-amino2-phenylimidazo[1,2-a]pyridine as corrosion inhibitor for C38 steel in 1M HCL," Der Pharma Chemica, vol. 4, no. 1, pp. 352364, 2012.

[6] A. C. Makrides and N. Hackerman, "Inhibition of acid dissolution of metals. I. Some general observations," Journal of Physical Chemistry, vol. 59, no. 8, pp. 707-710, 1955.

[7] G. Schmitt, "Application of inhibitors for acid media," British Corrosion Journal, vol. 19, no. 4, pp. 165-176, 1984.

[8] M. A. Quraishi and H. K. Sharma, "Thiazoles as corrosion inhibitors for mild steel in formic and acetic acid solutions," Journal of Applied Electrochemistry, vol. 35, no. 1, pp. 33-39, 2005.

[9] H.-L. Wang, H.-B. Fan, and J.-S. Zheng, "Corrosion inhibition of mild steel in hydrochloric acid solution by a mercaptotriazole compound," Materials Chemistry and Physics, vol. 77, no. 3, pp. 655-661, 2003.

[10] K. F. Khaled, O. A. Elhabib, A. El-Mghraby, O. B. Ibrahim, and M. A. M. Ibrahim, "Inhibitive effect of thiosemicarbazone derivative on corrosion of mild steel in hydrochloric acid solution," Journal of Materials and Environmental Science, vol. 1, no. 3, pp. 139-150, 2010.

[11] A. A. Al-Amiery, A. A. H. Kadhum, A. H. M. Alobaidy, A. B. Mohamad, and P. S. Hoon, "Novel corrosion inhibitor for mild steel in HCL," Materials, vol. 7, no. 2, pp. 662-672, 2014.

[12] B. M. Mistry, N. S. Patel, and S. Jauhari, "Heterocyclic organic derivative as corrosion inhibitor for mild steel in $1 \mathrm{~N} \mathrm{HCl}$," Archives of Applied Science Research, vol. 3, no. 5, pp. 300-308, 2011.

[13] A. E. Fouda, A. Al-Sarawy, and E. El-Katori, "Thiazole derivatives as corrosion inhibitors for C-steel in sulphuric acid solution," European Journal of Chemistry, vol. 1, no. 4, pp. 312$318,2010$.
[14] D. M. Gurudatt and K. N. Mohana, "Synthesis of new pyridine based 1,3,4-oxadiazole derivatives and their corrosion inhibition performance on mild Steel in $0.5 \mathrm{M}$ hydrochloric acid," Industrial and Engineering Chemistry Research, vol. 53, no. 6, pp. 2092-2105, 2014.

[15] T. K. Chaitra, K. N. Mohana, and H. C. Tandon, "Thermodynamic, electrochemical and quantum chemical evaluation of some triazole schiff bases as mild steel corrosion inhibitors in acid media," Journal of Molecular Liquids, vol. 211, pp. 1026-1038, 2015.

[16] K. N. Mohana and A. M. Badiea, "Effect of sodium nitrite-borax blend on the corrosion rate of low carbon steel in industrial water medium," Corrosion Science, vol. 50, no. 10, pp. 2939-2947, 2008.

[17] E. Baloglu, S. Ghosh, M. Lobera, and D. Schmidt, "Preparation of five membered heterocycle-containing benzamide and nicotinamide compounds as inhibitors of histone deacetylase (HDAC) enzymes," US Patent no. 0881181, 2011.

[18] M. M. Fahmy, R. R. Mohamed, and N. A. Mohamed, "Novel antimicrobial organic thermal stabilizer and co-stabilizer for rigid PVC," Molecules, vol. 17, no. 7, pp. 7927-7940, 2012.

[19] A. Paul, K. J. Thomas, V. P. Raphael, and K. S. Shaju, "Electrochemical and gravimetric corrosion inhibition investigations of a heterocyclic schiff base derived from 3-formylindole," IOSR Journal of Applied Chemistry, vol. 1, no. 6, pp. 17-23, 2012.

[20] V. R. Saliyan and A. V. Adhikari, "Inhibition of corrosion of mild steel in acid media by $\mathrm{N}^{\prime}$-benzylidene-3-(quinolin-4-ylthio) propanohydrazide," Bulletin of Material Science, vol. 31, no. 4, pp. 699-711, 2008.

[21] L. Fragoza-Mar, O. Olivares-Xometl, M. A. Domínguez-Aguilar, E. A. Flores, P. Arellanes-Lozada, and F. Jiménez-Cruz, "Corrosion inhibitor activity of 1,3-diketone malonates for mild steel in aqueous hydrochloric acid solution," Corrosion Science, vol. 61, pp. 171-184, 2012.

[22] F. El-Taib Heakal, A. S. Fouda, and M. S. Radwan, "Inhibitive effect of some thiadiazole derivatives on C-steel corrosion in neutral sodium chloride solution," Materials Chemistry and Physics, vol. 125, no. 1-2, pp. 26-36, 2011.

[23] L. Herrag, B. Hammouti, S. Elkadiri et al., "Adsorption properties and inhibition of mild steel corrosion in hydrochloric solution by some newly synthesized diamine derivatives: experimental and theoretical investigations," Corrosion Science, vol. 52, no. 9, pp. 3042-3051, 2010.

[24] F. Bentiss, M. Lagrenée, B. Elmehdi, B. Mernari, M. Traisnel, and $\mathrm{H}$. Vezin, "Electrochemical and quantum chemical studies of 3,5-di(n-tolyl)-4-amino-1,2,4-triazole adsorption on mild steel in acidic media," Corrosion, vol. 58, no. 5, pp. 399-407, 2002.

[25] K. Tebbji, B. Hammouti, H. Oudda, A. Ramdani, and M. Benkadour, "The inhibitive effect of bipyrazolic derivatives on the corrosion of steel in hydrochloric acid solution," Applied Surface Science, vol. 252, no. 5, pp. 1378-1385, 2005.

[26] M. Bouklah, B. Hammouti, M. Lagrenée, and F. Bentiss, "Thermodynamic properties of 2,5-bis(4-methoxyphenyl)1,3,4-oxadiazole as a corrosion inhibitor for mild steel in normal sulfuric acid medium," Corrosion Science, vol. 48, no. 9, pp. 2831-2842, 2006.

[27] L. M. Vračar and D. M. Dražić, "Adsorption and corrosion inhibitive properties of some organic molecules on iron electrode in sulfuric acid," Corrosion Science, vol. 44, no. 8, pp. 16691680, 2002.

[28] F. B. Ravari, A. Dadgarinezhad, and I. Shekhshoaei, "Investigation on two salen type schiff base compounds as corrosion 
inhibition of copper in $0.5 \mathrm{M} \mathrm{H}_{2} \mathrm{SO}_{4}$," Gazi University Journal of Science, vol. 22, no. 3, pp. 175-182, 2009.

[29] R. Atkin, V. S. J. Craig, E. J. Wanless, and S. Biggs, “The influence of chain length and electrolyte on the adsorption kinetics of cationic surfactants at the silica-aqueous solution interface," Journal of Colloid and Interface Science, vol. 266, no. 2, pp. 236244, 2003.

[30] A. K. Singh, G. Ji, R. Prakash, E. E. Ebenso, and A. K. Singh, "Cephamycin; a novel corrosion inhibitor for mild steel corrosion in $\mathrm{HCl}$ acid solution," International Journal of Electrochemical Science, vol. 8, no. 7, pp. 9442-9448, 2013.

[31] A. S. Fouda, M. N. Moussa, F. I. Taha, and A. I. Elneanaa, "The role of some thiosemicarbazide derivatives in the corrosion inhibition of aluminium in hydrochloric acid," Corrosion Science, vol. 26, no. 9, pp. 719-726, 1986.

[32] A. S. Fouda, A. A. El-Aal, and A. B. Kandil, "The effect of some phthalimide derivatives on the corrosion behaviour of copper in nitric acid," Anti-Corrosion Methods and Materials, vol. 52, no. 2, pp. 96-101, 2005.

[33] F. Bentiss, M. Lagrenee, M. Traisnel, and J. C. Hornez, "The corrosion inhibition of mild steel in acidic media by a new triazole derivative," Corrosion Science, vol. 41, no. 4, pp. 789803, 1999.

[34] E. A. Noor and A. H. Al-Moubaraki, "Thermodynamic study of metal corrosion and inhibitor adsorption processes in mild steel/1-methyl-4[4'(-X)-styryl pyridinium iodides/hydrochloric acid systems," Materials Chemistry and Physics, vol. 110, no. 1, pp. 145-154, 2008.

[35] E. S. Ferreira, C. Giacomelli, F. C. Giacomelli, and A. Spinelli, "Evaluation of the inhibitor effect of L-ascorbic acid on the corrosion of mild steel," Materials Chemistry and Physics, vol. 83, no. 1, pp. 129-134, 2004.

[36] G. M. Schmid and H. J. Huang, "Spectro-electrochemical studies of the inhibition effect of 4, 7-diphenyl-1, 10-phenanthroline on the corrosion of 304 stainless steel," Corrosion Science, vol. 20, no. 8-9, pp. 1041-1057, 1980.

[37] D. K. Yadav, B. Maiti, and M. A. Quraishi, "Electrochemical and quantum chemical studies of 3,4-dihydropyrimidin-2(1H)ones as corrosion inhibitors for mild steel in hydrochloric acid solution," Corrosion Science, vol. 52, no. 11, pp. 3586-3598, 2010.

[38] A. Ouchrif, M. Zegmout, B. Hammouti, S. El-Kadiri, and A. Ramdani, "1,3-Bis(3-hyroxymethyl-5-methyl-1-pyrazole) propane as corrosion inhibitor for steel in $0.5 \mathrm{M} \mathrm{H}_{2} \mathrm{SO}_{4}$ solution," Applied Surface Science, vol. 252, no. 2, pp. 339-344, 2005.

[39] T. Tsuru, S. Haruyama, and B. Gijutsu, "Corrosion inhibition of iron by amphoteric surfactants in $2 \mathrm{M} \mathrm{HCl,"} \mathrm{Journal} \mathrm{of} \mathrm{Japan}$ Society of Corrosion Engineering, vol. 27, pp. 573-581, 1978.

[40] M. A. Quraishi, M. Z. A. Rafiquee, S. Khan, and N. Saxena, "Corrosion inhibition of aluminium in acid solutions by some imidazoline derivatives," Journal of Applied Electrochemistry, vol. 37, no. 10, pp. 1153-1162, 2007.

[41] A. Yurt, A. Balaban, S. U. Kandemir, G. Bereket, and B. Erk, "Investigation on some Schiff bases as $\mathrm{HCl}$ corrosion inhibitors for carbon steel," Materials Chemistry and Physics, vol. 85, no. 2-3, pp. 420-426, 2004.

[42] F. Bentiss, M. Lebrini, M. Lagrenée, M. Traisnel, A. Elfarouk, and H. Vezin, "The influence of some new 2,5-disubstituted 1,3,4-thiadiazoles on the corrosion behaviour of mild steel in $1 \mathrm{M} \mathrm{HCl}$ solution: AC impedance study and theoretical approach," Electrochimica Acta, vol. 52, no. 24, pp. 6865-6872, 2007.
[43] S. Xia, M. Qiu, L. Yu, F. Liu, and H. Zhao, "Molecular dynamics and density functional theory study on relationship between structure of imidazoline derivatives and inhibition performance," Corrosion Science, vol. 50, no. 7, pp. 2021-2029, 2008.

[44] H. Zarrok, A. Zarrouk, R. Salghi et al., "Gravimetric and quantum chemical studies of 1-[4-acetyl-2-(4-chlorophenyl)quinoxalin-1(4H)-yl]acetone as corrosion inhibitor for carbon steel in hydrochloric acid solution," Journal of Chemical and Pharmaceutical Research, vol. 4, no. 12, pp. 5056-5066, 2012.

[45] P. Udhayakala, T. V. Rajendiran, and S. Gunasekaran, "Density expert committee on the functional theory investigations for the adsorption of some oxadiazole derivatives on mild steel," Journal of Advanced Scientific Research, vol. 3, no. 3, pp. 67-74, 2012.

[46] J. Fang and J. Li, "Quantum chemistry study on the relationship between molecular structure and corrosion inhibition efficiency of amides," Journal of Molecular Structure: THEOCHEM, vol. 593, no. 1-3, pp. 179-185, 2002.

[47] E. E. Ebenso, D. A. Isabirye, and N. O. Eddy, "Adsorption and quantum chemical studies on the inhibition potentials of some thiosemicarbazides for the corrosion of mild steel in acidic medium," International Journal of Molecular Sciences, vol. 11, no. 6, pp. 2473-2498, 2010.

[48] I. B. Obot, N. O. Obi-Egbedi, and S. A. Umoren, "Adsorption characteristics and corrosion inhibitive properties of clotrimazole for aluminium corrosion in hydrochloric acid," International Journal of Electrochemical Science, vol. 4, no. 6, pp. 863877, 2009.

[49] G. Gao and C. Liang, "Electrochemical and DFT studies of $\beta$ amino-alcohols as corrosion inhibitors for brass," Electrochimica Acta, vol. 52, no. 13, pp. 4554-4559, 2007.

[50] N. Khalil, "Quantum chemical approach of corrosion inhibition," Electrochimica Acta, vol. 48, no. 18, pp. 2635-2640, 2003.

[51] J. Zhang, Y.-H. Kan, H.-B. Li, Y. Geng, Y. Wu, and Z.-M. Su, "How to design proper $\pi$-spacer order of the D- $\pi$-A dyes for DSSCs? A density functional response," Dyes and Pigments, vol. 95, no. 2, pp. 313-321, 2012. 

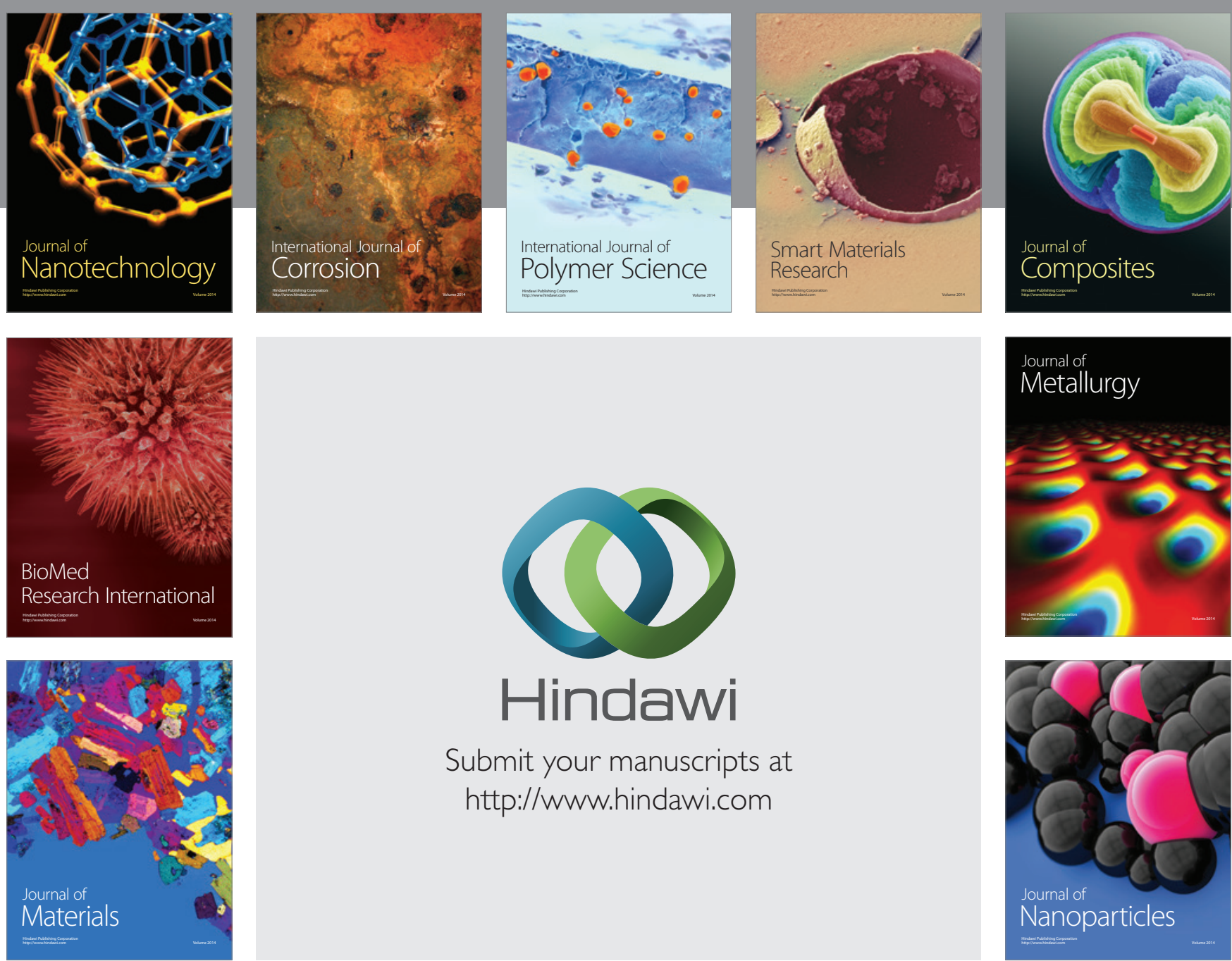

\section{Hindawi}

Submit your manuscripts at

http://www.hindawi.com

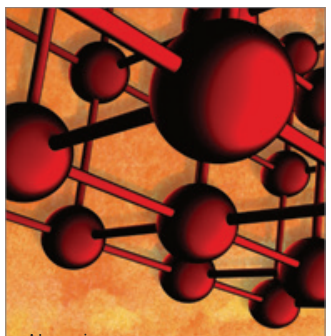

Materials Science and Engineering
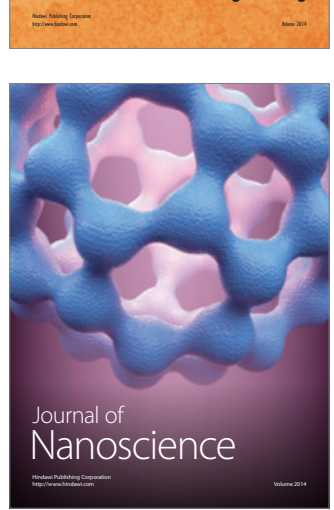
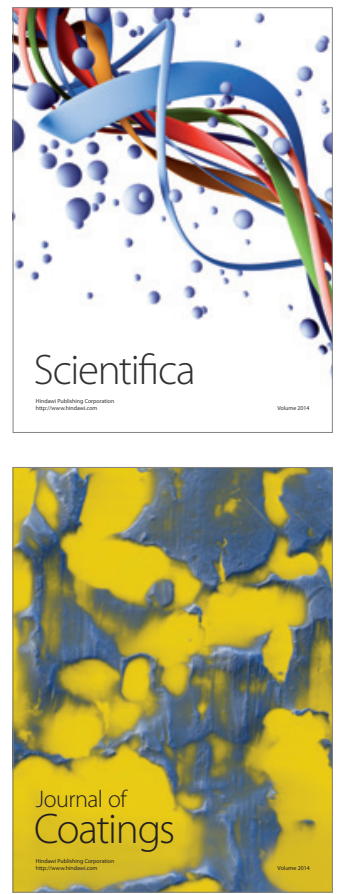
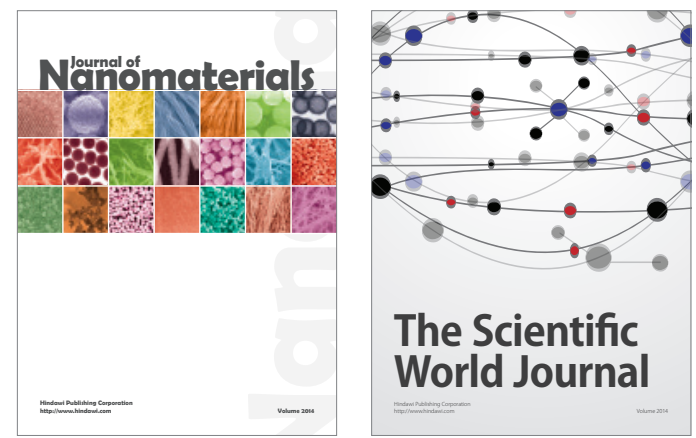

The Scientific World Journal
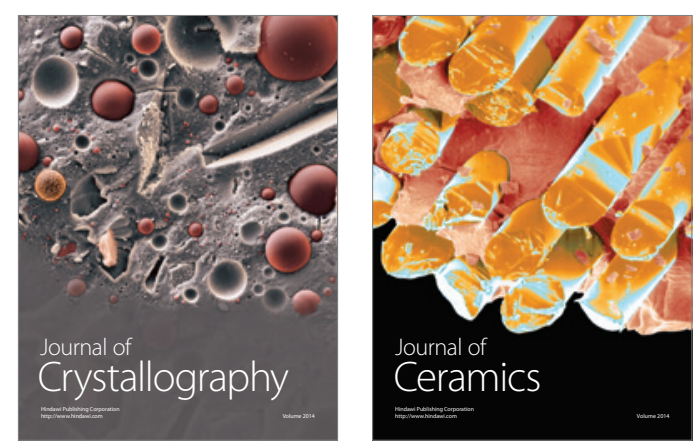
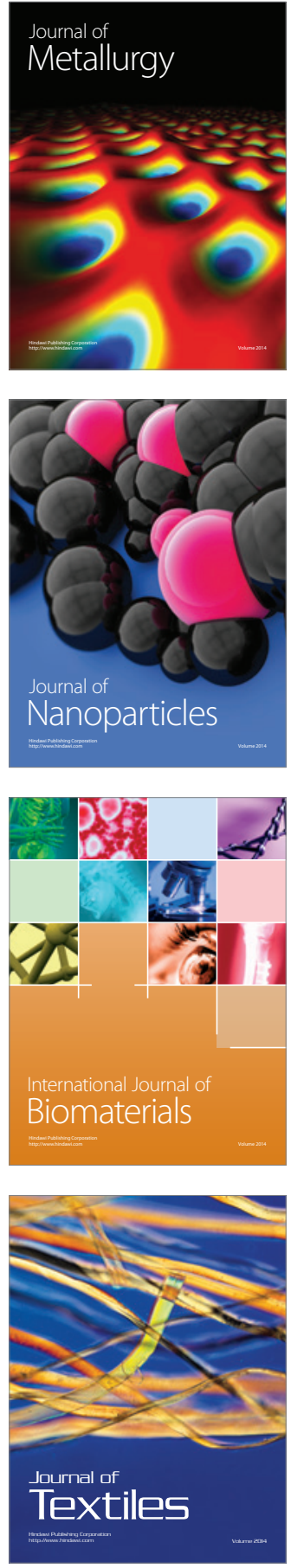